\title{
Fiber Reinforced Polymer (FRP) Confined Circular Columns: Compressive Strength Assessment
}

\author{
Christos G. Papakonstantinou
}

Dept of Civil Engineering, University of Thessaly, Volos, 38334, Greece

Received 16 June 2020; Accepted 16 December 2020

\begin{abstract}
Fiber Reinforced Polymer (FRP) composites may be successfully used in numerous structural strengthening applications. One of these applications is as a confining material for reinforced concrete structural elements. Research has shown its effectiveness both in seismic retrofit of existing reinforced concrete columns as well as in new construction of concretefilled composite tubes as earthquake-resistant columns. Several researchers have conducted experiments and introduced analytical models, mostly empirical, fitted with relatively limited experimental data. These models can be used to predict the confined concrete strength of cylindrical specimens. In this article, a series of twelve analytical models are evaluated using a quite extensive experimental database. The database includes a total of 639 cylindrical concrete specimens confined with carbon or glass fibers. The evaluation of each model's performance was carried out using novel statistical methods. Generally, it was observed that the type of the fibers used does affect the analytical model's prediction accuracy. In general, newer models have higher efficacy compared to older ones, and the equations suggested by the Eurocodes provide safe design tools regardless of unconfined compressive concrete strength and type of confining material. Moreover, using this extended database an empirical model was developed, and its performance compared to that of the twelve models. The results indicate that the simple proposed model exhibits excellent all-around performance.
\end{abstract}

Keywords: confined concrete, fiber-reinforced polymer, compressive strength, composite materials, concrete confinement

\section{Introduction}

The need for high load capacity and safety in structures led to the use of different methods for strengthening of existing structures. Many efforts have been made to find effective methods with which the load capacity of structural elements will be maximized. One of the most effective ways of structural strengthening is concrete confinement, especially for reinforced concrete columns. The confinement occurs because of the wrapping of the lateral surface of a concrete element (e.g. concrete cylinder, beam or slab) using Fiber Reinforced Polymers (FRPs). The thickness of each FRP layer varies and depends on the designer's needs. Usually, the use of a smaller number of FRP layers is preferable, in order to avoid delamination. The confining material is attached around the concrete surface, not allowing the expansion of the concrete element in high stress conditions. More specifically, concrete is characterized by high compressive strength, when subjected to axial compressive stress. Nevertheless, the value of the compressive strength $\left(\mathrm{f}^{\prime} \mathrm{c}\right)$, which occurs during fracture, is specific and always lower than the compressive strength of a similar concrete cylinder confined by FRPs ( $\left.\mathrm{f}^{\prime}{ }_{\mathrm{cc}}\right)$. This occurs because when concrete is compressed axially, it expands laterally. The FRP reacts to concrete lateral expansion and thus is stressed axially. Thus, FRPs with higher tensile strength will result in higher concrete confined strength.
The efficacy of the confinement greatly depends upon the confining materials. There are several types of FRPs according to the fiber type. Although carbon and glass fibers (CFRPs and GFRPs) are the most common types of FRPs, aramid and basalt fibers are used too. The type of fibers determines the properties of the confining material. Usually the Modulus of Elasticity (E) and tensile strength of the CFRPs are higher than that of GFRPs. Nevertheless, in both cases the confinement of the concrete element results in higher ultimate compressive loads [1].

It would be very useful to be able to accurately predict the compressive strength of a concrete cylindrical structural element wrapped with FRPs. Consequently, during the last thirty years numerous researchers have suggested possible analytical models [2-5], and design guidelines [6] have been adopted by international design codes. In almost all cases these analytical models were calibrated using experimental data.

This article provides an analysis and comparison of twelve confined concrete strength models using a new extensive experimental database. Using each model, the compressive strengths of the confined concrete cylindrical specimens from the experimental database are calculated. The accuracy of each model is measured by the convergence of the experimental (database results) and predicted (calculated) results, through two different statistical methods. Finally, one of the older models is revised in order to achieve better accuracy and to demonstrate that empirical equations can benefit from a larger dataset. 


\section{Methodology - Experimental Database}

A total of 639 cylindrical confined concrete specimens were identified from the literature [1, 4, 7-57]. For each reported specimen data such as cylinder diameter, length, unconfined concrete strength, FRP thickness, FRP tensile strength, FRP Modulus were collected. All these data were used to create an experimental database. The majority of the concrete cylinders were confined using Carbon Fiber Reinforced Polymers (a total of 446), 157 specimens were confined with Glass Fiber Reinforced Polymer, while 36 specimens were unconfined and were used as reference. Although other materials have been used for confinement as well their number is limited and thus statistically insignificant. The specimen's diameter varied from 51 to $610 \mathrm{~mm}$ and the unconfined concrete strength from 8.5 to $112.6 \mathrm{MPa}$. Another variable was the type and thickness of the fabric used for confinement.

Low unconfined concrete strength specimens were used mostly in experiments with CFRP confinement. Cánovas et al.[29], Ilki et al. [49], Li et al [51] and Shahawy et al. [41] used low strength specimens. The lowest unconfined strength was $8.5 \mathrm{MPa}$ and was used by Canovas et al.[29]. The largest number of experiments utilized CFRP and GFRP wrapping with an unconfined strength that varies from 24 to $50 \mathrm{MPa}$ $[10,24,46,48,52]$. High strength concrete ranging from 51 to $113 \mathrm{MPa}$ was used in a limited number of specimens mostly when CFRP was used for confinement [18, 24, 30, 44, 46, 50]. The experimental database includes normal and high strength concrete specimens confined with GFRP. Normal compressive strength ranged from 24 to $48 \mathrm{MPa}[10,21,24]$, while the highest unconfined concrete strength was $108 \mathrm{MPa}$ [21].

Fiber properties constitute another significant variable in the database. It is easily observed that reported FRP properties vary significantly. It is important to note, that properties such as the modulus of elasticity, and tensional strength, depend upon the method that was used to obtain them. More particularly, properties would be different if the material characterization tests have been performed on pure fibers versus composite laminates (coupons). When collecting experimental published data one can assume information from the reported FRP thickness. The thickness may provide information on whether the reported properties belong to that of the dry fibers or the FRP composite. It was noted that most researchers simply mention the material properties provided by the manufacturer without performing tests on coupons based on laminates made with the fibers. It is well documented that dry fibers do not have the same mechanical properties as a fiber composite laminate [58], so creating a database and even following design guidelines can become a quite challenging task.

In most of the confined specimens the reported FRP thickness, $t_{F R P}$,ranges between 0.3 and $2 \mathrm{~mm}$. However, in some cases the reported thickness was even less than $0.3 \mathrm{~mm}$ $[8,35,44]$. The thinnest reported FRP was $0.05 \mathrm{~mm}[41,44]$. On the contrary Youseff [20] used specimens confined with FRP thickness of more than $5 \mathrm{~mm}$. All researchers reported that the concrete specimens were measured, the surface was cleaned and finally the FRP was applied on the perimeter of the cylinder according to the specifications of the FRP manufacturer. Mechanical properties such as elastic moduli and maximum axial stress vary significantly between the fibers recorded in the database. More specifically the moduli varied from 8.5 to $612 \mathrm{GPa}$, while the fracture stress from 135 to $4400 \mathrm{MPa}$. This large variation is a testament of the varying values reported by researchers, mixing fiber and laminate experimental data as mentioned previously.

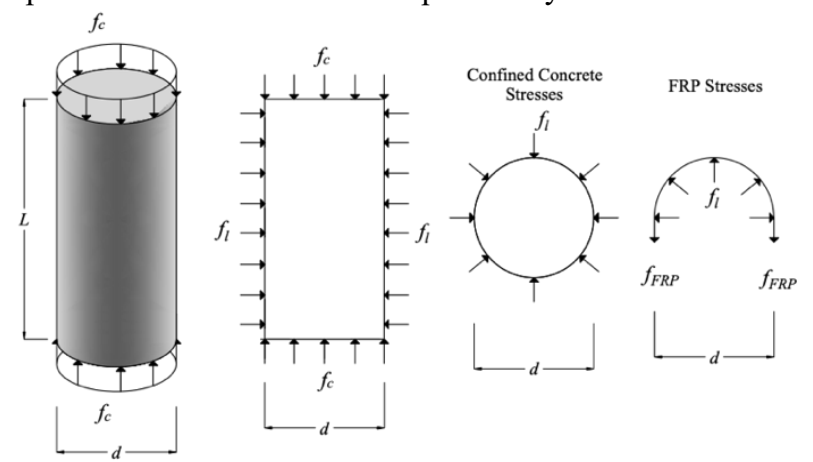

Fig. 1. Scheme of stresses due to FRP confining action in circular concrete element.

Under triaxial compressive stresses, the concrete cylindrical elements are subjected to main compressive stresses $f_{c}$ uniformly applied along the longitudinal axis of the column and lateral confining pressure $f_{l}$ (Figure 1). As the confined concrete is compressed, it tries to expand in the hoop direction. The FRP jacket which is therefore loaded uniaxially, reacts to this expansion and thus creates a reactive confining radial pressure $f_{l}$ at the FRP-concrete interface (Figure 1) which can be expressed as:

$f_{l}=\frac{2 \cdot t \cdot f_{F R P}}{d}$

where $t, f_{\mathrm{FRP}}$ and d designate the FRP thickness, FRP hoop tensile stress and diameter of concrete cylinder, respectively.

The concrete confinement may be provided by passive means such as steel (hoops, ties, spirals, jackets, etc.) and FRP (sheets, tubes, etc.) confinement around the concrete core, or actively through hydrostatic pressure. Unlike structural steel, FRP behaves purely elastically until failure. The inward radial stress increases with the lateral expansion of the concrete, so that the assumption of constant confining pressure cannot be valid. Thus, the models originally developed for steel hoop confinement may unsafely overestimate the strength of FRPconfined columns. However, most empirical confinement models adopt quite well to the Mohr-Coulomb failure criterion either for actively (hydrostatic pressure) or passively (steel, FRP) confined concrete [55]. In this study a series of 12 highly regarded models from 1988 to 2016 is evaluated using the previously described experimental database that contains cylindrical concrete specimens confined with carbon and glass fiber polymers.

\section{Analytical Models}

In 1988, Fardis and Khalili [3] where the first to develop a model based on the equation proposed by Richard et al. [59] (Eq. 2) and having created a database of concrete columns confined with FRP and unconfined strength, $f^{\prime}{ }_{c o}$ from 20 to 50 $\mathrm{MPa}$, they tried to best calculate the coefficient $k_{l}$ of Eq. 2 and provide an accurate model for the calculation of $f_{c c}^{\prime}$ (Eq. 3):

$f^{\prime}{ }_{c c}=\mathrm{f}_{c o} *\left[\frac{\mathrm{f}_{\mathrm{l}}}{\mathrm{f}_{\mathrm{co}}} \mathrm{k}_{1}+1\right]$

$f^{\prime}{ }_{c c}=\left(1+4,1 * \frac{\mathrm{f}_{\mathrm{l}}}{\mathrm{f}_{\mathrm{co}}}\right) * \mathrm{f}_{\mathrm{co}}$

In 1994 Saadatmanesh et al. [4] suggested a model which was first proposed by Mander et al. [60] for confined concrete 
cylinders considering the compressive strength of unconfined concrete cylinders $\left(\mathrm{f}^{\prime}{ }_{\mathrm{co}}\right)$ and the lateral stress $\mathrm{f}_{1}$ calculated using Eq.1. Hence, Saadatmanesh's equation is:

$\mathrm{f}^{\prime}{ }_{\mathrm{cc}}=\left(2,254 * \sqrt{1+7,94 *\left(\frac{\mathrm{f}_{\mathrm{l}}}{\mathrm{f}_{\mathrm{co}}}\right)}-2 * \frac{\mathrm{f}_{\mathrm{l}}}{\mathrm{f}_{\mathrm{co}}}-1,254\right) * \mathrm{f}_{\mathrm{co}}^{\prime}$

Later on, Spoelstra \& Monti [2], based on the analysis of their experimental results, suggested an equation of calculation of the stress $\mathrm{f}_{\mathrm{cc}}$ and strain $\varepsilon_{\mathrm{cc}}^{\prime}$ of the confined concrete. The following equation (Eq. 5) constitutes the final expression of Spoelstra \& Monti's model:

$\mathrm{f}^{\prime}{ }_{\mathrm{cc}}=\mathrm{f}_{\mathrm{co}}^{\prime} *\left(0.2+3 * \sqrt{\frac{\mathrm{f}_{\mathrm{l}}}{\mathrm{f}_{\mathrm{co}}}}\right)$

This model was developed based on experimental data from concrete cylinders with $f_{c o}^{\prime}$ from 30 to $50 \mathrm{MPa}$. Consequently, possible inaccuracy of the model when very low or high strength concrete cylinders are used, may be expected.

Toutanji [5] conducted an experimental survey gathering a relatively large number of confined concrete specimens tested in uniaxial compression. Based on the expressions of Richard et al. [59] and Mander et al. [60], he suggested a new analytical model for the calculation of confined concrete strength, $f^{\prime}{ }_{c c}$, using either CFRP or GFRP for confinement. He recognized that there is a relationship that describes the efficiency of confinement in terms of the ratio $f_{l} / f^{\prime}{ }_{c o}$. Using the experimental database, he tried to calibrate the coefficient $k_{\text {eff }}$ (confinement efficiency, $f_{l} / f^{\prime}{ }_{c o}$ ) using the experimental data and came up with (Eq. 6). Hence, the final expression of $f^{\prime}{ }_{c c}$ is given by Eq. 7 .

$\mathrm{k}_{\mathrm{eff}}=\left(3,50 *\left(\frac{\mathrm{f}_{\mathrm{l}}}{\mathrm{f}_{\mathrm{co}}}\right)^{-0,15}\right)$

$\mathrm{f}^{\prime}{ }_{\mathrm{cc}}=\mathrm{f}_{{ }_{\mathrm{co}}}^{\prime} *\left[1+3,5 *\left(\frac{\mathrm{f}_{\mathrm{l}}}{\mathrm{f}_{\mathrm{co}}}\right)^{0,85}\right]$

Xiao $\kappa \alpha \mathrm{l} \mathrm{Wu}$ [18] suggested an analytical model based on 27 concrete cylinders with CFRP confinement.

$\mathrm{f}^{\prime}{ }_{\mathrm{cc}}=\mathrm{f}^{\prime}{ }_{\mathrm{co}} *\left(\mathrm{a}+\mathrm{k} * \frac{\mathrm{f}_{\mathrm{r}}}{\mathrm{f}_{\mathrm{co}}}\right)$

The value of the coefficient $\alpha$ was specified experimentally $(\alpha=1.10)$ and the value of $k$ is calculated by Eq. 9 as follows:

$$
\begin{aligned}
& \mathrm{k}=4.1-0.75 * \frac{\mathrm{f}^{\prime}{ }^{2}{ }_{\mathrm{co}}}{\mathrm{C}_{\mathrm{j}}} \\
& \mathrm{C}_{\mathrm{j}}=\frac{2 * \mathrm{t}_{\mathrm{f}} * \mathrm{E}_{\mathrm{FRP}}}{\mathrm{D}}
\end{aligned}
$$

According to the Eurocode 2 [61] the confined strength can be calculated using Eq. 11 or 12 depending upon the lateral confining stress. $\mathrm{f}^{\prime}{ }_{\mathrm{cc}}=\mathrm{f}_{\mathrm{ck}, \mathrm{c}}=\mathrm{f}_{\mathrm{ck}} *\left(1.000+\frac{5 * \sigma_{2}}{\mathrm{f}_{\mathrm{ck}}}\right)$

when $\sigma_{2} \leq 0.05 f_{\text {ck }}$

$\mathrm{f}^{\prime}{ }_{\mathrm{cc}}=\mathrm{f}_{\mathrm{ck}, \mathrm{c}}=\mathrm{f}_{\mathrm{ck}} *\left(1.125+\frac{2.50 * \sigma_{2}}{\mathrm{f}_{\mathrm{ck}}}\right)$

when $\sigma_{2}>0.05 f_{\text {ck }}$

where: $f_{c k}$ is the unconfined concrete compressive strength, $\mathrm{f}_{\mathrm{ck}, \mathrm{c}}$ is the confined concrete compressive strength (or $\mathrm{f}_{\mathrm{cc}}$ ) and, $\sigma_{2}$ is the lateral confining stress, similar to $\mathrm{f}_{\mathrm{l}}$, which may also be calculated using Eq.13.

Furthermore, according to the Eurocode 8 [6], the confining lateral stress provided by the FRP tape or fabric should be limited to a maximum achievable FRP stress which corresponds to an ultimate jacket strain, $\varepsilon_{\text {ju }}$. Equations 13 and 14 shown below are essentially the same equation as Eq.1.:

$\mathrm{f}_{\mathrm{l}}=0,5 * \rho_{\mathrm{FRP}} * \mathrm{E}_{\mathrm{FRP}} * \varepsilon_{\mathrm{ju}}$

$\rho_{\mathrm{FRP}}=\frac{4 * \mathrm{t}_{\mathrm{f}}}{\mathrm{D}}$

Aire et al. [13] conducted a series of experiments using confined concrete cylinders under axial compression. The cylinders were confined with CFRP and GFRP sheets with unconfined concrete strength ranging from 30 up to $70 \mathrm{MPa}$. The proposed analytical model is given by Equations 15 and 16:

$\mathrm{f}^{\prime}{ }_{\mathrm{cc}}=\mathrm{f}^{\prime}{ }_{\mathrm{co}}+\mathrm{k}_{1} * \mathrm{f}_{\mathrm{l}}$

where: $\quad \mathrm{k}_{1}=6,7 * \mathrm{f}_{\mathrm{l}}^{-0,17}$

Benzaid et al. [62] suggested an equation for the calculation of concrete confined strength, which was based on experimental data from CFRP confined regular strength (29 to $62 \mathrm{MPa}$ ) concrete specimens:

$$
\mathrm{f}^{\prime}{ }_{\mathrm{cc}}=\mathrm{f}^{\prime}{ }_{\mathrm{co}} *\left(1+1,6 * \frac{\mathrm{f}_{\mathrm{l}}}{\mathrm{f}_{\mathrm{co}}}\right)
$$

Csuka and Kollar [63] suggested the use of an efficiency factor, $\kappa_{\varepsilon}$, the value of which differentiates according to the confinement material. Generally speaking, the coefficient $\kappa_{\varepsilon}$ may take values within the region of 0.6 and 1.0. Equation 18 defines the actual confining stress as follows:

$$
\mathrm{f}_{\mathrm{l}, \mathrm{a}}=\kappa_{\varepsilon} * \mathrm{f}_{\mathrm{l}}
$$

However, a statistical analysis identified the values of 0.68 and 0.793 to provide the best results for CFRP and GFRP respectively.

Consequently, the following equations (Eq. 19 and Eq. 20) may be used to calculate the compressive strength $f^{\prime}{ }_{c c}$ of the confined cylinders by CFRP and GFRP respectively.

$$
\begin{aligned}
& \mathrm{f}_{c c}^{\prime}=\frac{\left[\left(0.68 * \mathrm{f}_{\mathrm{l}}+\sqrt{10.16 * 0.68 * \mathrm{f}_{\mathrm{l}}, \mathrm{f}^{\prime}{ }_{\mathrm{co}}+\mathrm{f}^{\prime}{ }^{2}{ }^{2}}\right)+\left(0.68 * \mathrm{f}_{\mathrm{l}}+\sqrt{10.16 * 0.68 * \mathrm{f}_{\mathrm{l}} * \mathrm{f}^{\prime} \mathrm{co}}\right)\right]}{2} \\
& \mathrm{f}^{\prime}{ }_{\mathrm{cc}}=\frac{\left[\left(0.793 * \mathrm{f}_{1}+\sqrt{10.16 * 0.793 * \mathrm{f}_{1}, \mathrm{f}^{\prime}{ }_{\mathrm{co}}+\mathrm{f}^{\prime}{ }_{\mathrm{co}}^{2}}\right)+\left(0.793 * \mathrm{f}_{1}+\sqrt{10.16 * 0.793 * \mathrm{f}_{\mathrm{l}} * \mathrm{f}_{\mathrm{co}}}\right)\right.}{2}
\end{aligned}
$$


Ozbakkaloglu and Lim [64] on the other hand, provided a quite different methodology to calculate the confined concrete strength. The authors using a statistical analysis of a large experimental database suggested the use of the strain reduction, $\mathrm{k}_{\mathrm{ef}}$, which may be calculated as follows:

$$
\mathrm{k}_{\mathrm{ef}}=0,9-2,3 * \mathrm{f}^{\prime}{ }_{\text {со }} * 10^{-3}-0,75 * \mathrm{E}_{\mathrm{FRP}} * 10^{-6}
$$

and the final actual stress due to the confinement may be calculated as:

$$
\mathrm{f}_{\text {lu, }}=\mathrm{k}_{\mathrm{ef}} * \mathrm{f}_{\mathrm{l}}
$$

Furthermore, the factor of $\mathrm{k}_{1}$ is calculated by the following expression (Eq. 23) provided it is smaller than $\mathrm{f}^{\prime}{ }_{\mathrm{co}}{ }^{1.65}$.

$$
\begin{aligned}
& \mathrm{k}_{\mathrm{l}}=\frac{2 * \mathrm{E}_{\mathrm{FRP}} * \mathrm{t}_{\mathrm{f}}}{\mathrm{D}} \leq \mathrm{f}_{\mathrm{co}}^{\prime 1.65} \\
& \mathrm{c}_{1}=1+0.0058 * \frac{\mathrm{k}_{1}}{\mathrm{f}^{\prime} \mathrm{co}_{\mathrm{co}}}
\end{aligned}
$$

Additionally, the Eq. 25 represents the lowest value of confining stress $\mathrm{f}^{\prime}{ }_{\mathrm{lo}}$. It is obvious it is related to the factors $\mathrm{k}_{\mathrm{l}}$ and $\mathrm{f}^{\prime}{ }_{\mathrm{co}}$.

$$
\mathrm{f}^{\prime}{ }_{\mathrm{lo}}=\mathrm{k}_{\mathrm{l}} *\left(0.43+0.009 * \frac{\mathrm{k}_{\mathrm{l}}}{\mathrm{f}^{\prime}{ }_{\mathrm{co}}}\right) *\left(\frac{\mathrm{f}_{\mathrm{co}}}{22000 *\left(\frac{\mathrm{f}_{\mathrm{co}}}{10}\right)^{0.30}}\right)
$$

Thus, the final equation for the calculation of the confined strength is given by:

$$
\mathrm{f}^{\prime}{ }_{\mathrm{cc}}=\mathrm{c}_{1} * \mathrm{f}^{\prime}{ }_{\mathrm{co}}+\mathrm{k}_{1} *\left(\mathrm{f}_{\mathrm{lu}, \mathrm{a}}-\mathrm{f}^{\prime}{ }_{\mathrm{lo}}\right)
$$

Girgin [65] used an experimental database of concrete unconfined cylinders ( $\mathrm{f}_{\text {co }}$ from 7 to $108 \mathrm{MPa}$ ) and based on principles coming from geotechnical-mechanics, tried to correlate the strength of confined columns f'cc. Girgin's model is based on Johnston's criterion [66] that introduces the material coefficients B and M. B describes the nonlinearity of the strength criterion and $\mathrm{M}$ defines the slope of the failure envelope at $\mathrm{fl}=0$.

$$
\begin{aligned}
& \mathrm{B}=1-0.0172 *\left(\log \left(\mathrm{f}^{\prime}{ }_{\text {co }}\right)\right)^{2} \\
& \mathrm{M}=0.0035 * \mathrm{f}^{\prime}{ }_{\text {co }}{ }^{2}-0.056 * \mathrm{f}^{\prime}{ }_{\text {co }}+2.83 \\
& \mathrm{M}=0.0003 * \mathrm{f}^{\prime}{ }_{\text {co }}{ }^{2}-0.076 * \mathrm{f}^{\prime}{ }_{\text {co }}+5.46
\end{aligned}
$$

If the value of $\mathrm{f}_{\text {co }}$ is between 7 and $24 \mathrm{MPa}$, the variable $\mathrm{M}$ will be defined by the Eq. 28a. If it is higher than $24 \mathrm{MPa}$, the equation $28 \mathrm{~b}$ should be used.

Thus, the final expression of $\mathrm{f}^{\prime}{ }_{\mathrm{cc}}$ is given by the following equation:

$$
\mathrm{f}^{\prime}{ }_{\mathrm{cc}}=\mathrm{f}^{\prime}{ }_{\mathrm{co}} *\left(1+\frac{\mathrm{M}}{\mathrm{B}} * \frac{\mathrm{f}_{\mathrm{l}}}{\mathrm{f}_{\mathrm{co}}}\right)^{\mathrm{B}}
$$

Touhari and Mittiche-Kettab [24] tested fifty four confined concrete cylindrical specimens, with unconfined strengths that ranged from 24 up to $61.7 \mathrm{MPa}$. Based on the experimental findings they suggested a general expression for the calculation of the confined concrete strength, $\mathrm{f}_{\mathrm{cc}}$, using two variables $\mathrm{M}$ and $\mathrm{N}$, which according to the authors depend upon the type of material and unconfined concrete strength, $\mathrm{f}_{\text {co. }}$. $\mathrm{f}^{\prime}{ }_{\mathrm{cc}}=\mathrm{f}^{\prime}{ }_{\mathrm{co}} *\left(1+\mathrm{N} *\left(\frac{\mathrm{f}_{\mathrm{l}}}{\mathrm{f}_{\mathrm{co}}}\right)^{\mathrm{M}}\right)$

Since the measured FRP strain at failure $\left(\varepsilon_{h, \text { rep }}\right)$, was smaller than the theoretical ultimate FRP strain $\left(\varepsilon_{F R P, u}\right)$, the authors suggested the use of a reduction factor, $k_{e f}$. The reduction factor is being used to limit the lateral confinement stress, $f_{l}$ as shown in Eq. 32. Thus, instead of using the lateral confinement stress, $f_{l}$, it is proposed (see Eq. 33) to use the effective lateral confinement stress, $f_{l, e f f}$.

$\mathrm{k}_{\mathrm{ef}}=\frac{\varepsilon_{\mathrm{h}, \mathrm{rep}}}{\varepsilon_{\mathrm{FRP}, \mathrm{u}}}$

$\mathrm{f}_{\mathrm{l}}=\frac{\mathrm{f}_{\mathrm{l} \text {,eff }}}{\mathrm{k}_{\mathrm{ef}}}$

${\mathrm{f}^{\prime}}^{\prime}{ }_{\mathrm{cc}}=\mathrm{f}^{\prime}{ }_{\text {co }} *\left[1+\mathrm{N} * \mathrm{k}_{\mathrm{ef}}^{\mathrm{M}} *\left(\frac{\mathrm{f}_{\mathrm{l}, \mathrm{eff}}}{\mathrm{f}^{\prime}{ }_{\mathrm{co}}}\right)^{\mathrm{M}}\right]$

Based on the experimental data, the values of $\mathrm{M}, \mathrm{N}$ were quantified as shown in Eq.34 and Eq.35 for CFRP and GFRP respectively:

$$
\begin{gathered}
\mathrm{f}^{\prime}{ }_{\mathrm{cc}}=\mathrm{f}^{\prime}{ }_{\mathrm{co}} *\left(1+3,58 *\left(\frac{\mathrm{f}_{\mathrm{l}, \mathrm{eff}}}{\mathrm{f}_{\mathrm{co}}^{\prime}}\right)^{0,997}\right) \\
\mathrm{f}_{\mathrm{cc}}^{\prime}=\mathrm{f}^{\prime}{ }_{\mathrm{co}} *\left(1+2,50 *\left(\frac{\mathrm{f}_{\mathrm{l}, \mathrm{eff}}}{\mathrm{f}_{\mathrm{co}}{ }^{1,027}}\right)\right.
\end{gathered}
$$

Based on the experimental results of their database, Touhari and Mittiche-Kettab [24] calculated an average value for $\mathrm{k}_{\mathrm{ef}}$, which was equal to 0,79 for CFRP confined specimens and 0,74 for GFRP confined specimens. Given these values for $\mathrm{k}_{\mathrm{ef}}$ the authors propose the use of Eq. 36 for CFRP and Eq.37 for GFRP confinement.

$$
\begin{aligned}
& \mathrm{f}^{\prime}{ }_{\mathrm{cc}}=\mathrm{f}^{\prime}{ }_{\mathrm{co}} *\left(1+2,8 *\left(\frac{\mathrm{f}_{\mathrm{l}}}{\mathrm{f}_{\mathrm{co}}}\right)\right) \\
& \mathrm{f}^{\prime}{ }_{\mathrm{cc}}=\mathrm{f}^{\prime}{ }_{\mathrm{co}} *\left(1+1,85 *\left(\frac{\mathrm{f}_{\mathrm{l}}}{\mathrm{f}_{\mathrm{co}}}\right)\right)
\end{aligned}
$$

As described some models are more elaborate while others consist of a simple equation, and while most do not make the distinction between CFRP and GFRP others offer different equations depending on the material. All twelve models are fundamentally based on the main failure criterion originally described by Coulomb in 1776 [67] and concluded by Mohr in 1900 [68]. Although it may not be the most accurate model, its simplicity and wide acceptance renders it the most attractive by all researchers.

\section{Results and Discussion}

The twelve models described previously were evaluated using the experimental database of 639 confined specimens. Using the equations specified in each model, a theoretical prediction was calculated for each tested specimen in the experimental database. For a theoretically perfect model, the ratio of theoretical to experimental confined compressive strength should be equal to exactly one. Ratio values greater than one 
indicate that the model overestimates the actual confined strength while the opposite occurs when the ratio is lower than one.

Since many models provide separate equations for Carbon and Glass fiber composites, each of the twelve models was evaluated separately for CFRP and GFRP confinement. Figures 2 to 13 show graphs of predicted vs reported experimental confined strengths with CFRP and GFRP for each examined model. In each graph a diagonal line indicates the theoretically ideal condition. Points that lay below this diagonal line suggest that the examined model overestimates the confined strength, whereas points above the diagonal denote that the model underestimates the actual confined strength.

Figure 2 shows that one of the early models, that of Fardis and Khalili [3], which was derived from a relatively small number of experimental data, is effective at low strengths, but as the strength increases the model overestimates significantly the actual confined strength. In terms of GFRP confinement, the model seems to overestimate the confined strength regardless of the confined strength magnitude. Similar performance can be identified from most of the remaining models such as the Saadatmanesh et al. [4] (Figure 3), Toutanji [5] (Figure 5), Xiao kal Wu [18] (Figure 6), Aire et al. [13] (Figure 8).
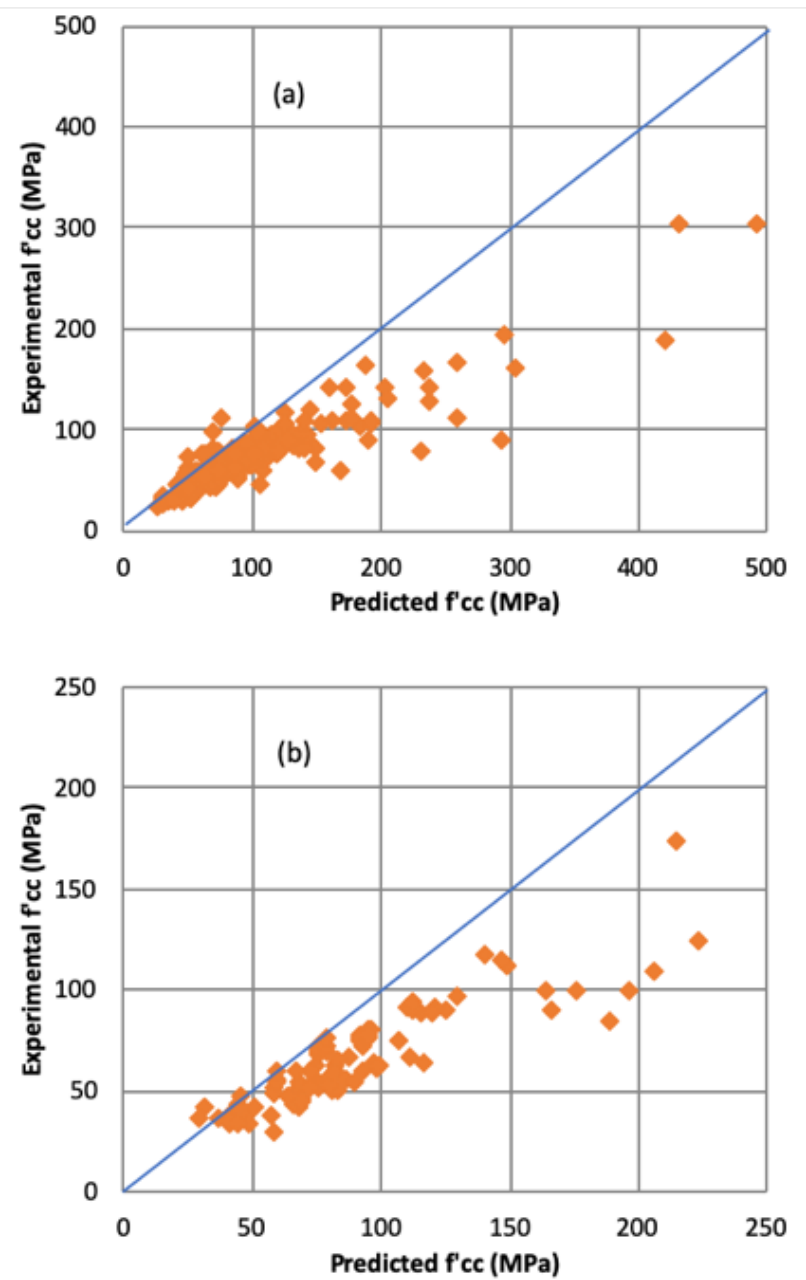

Fig. 2. Experimental vs predicted confined compressive strength using the Fardis and Khalili [3] model, (a) for CFRP and (b) for GFRP confinement.
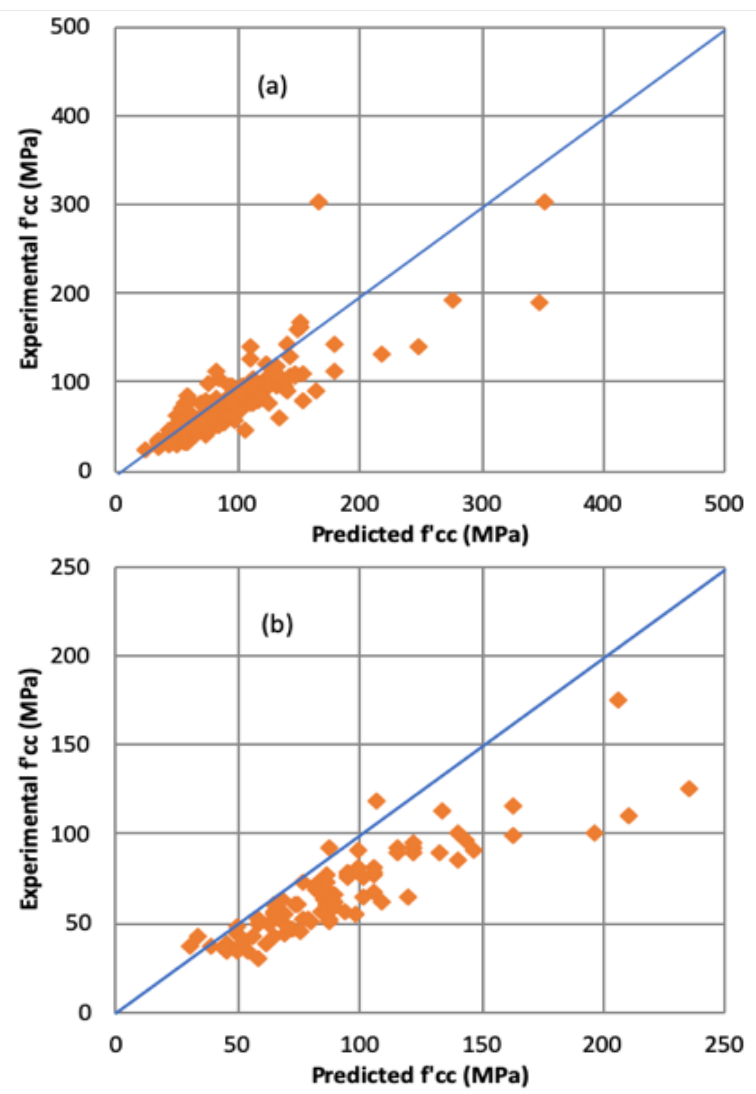

Fig. 3. Experimental vs predicted confined compressive strength using the Saadatmanesh et al. [4] model, (a) for CFRP and (b) for GFRP confinement.
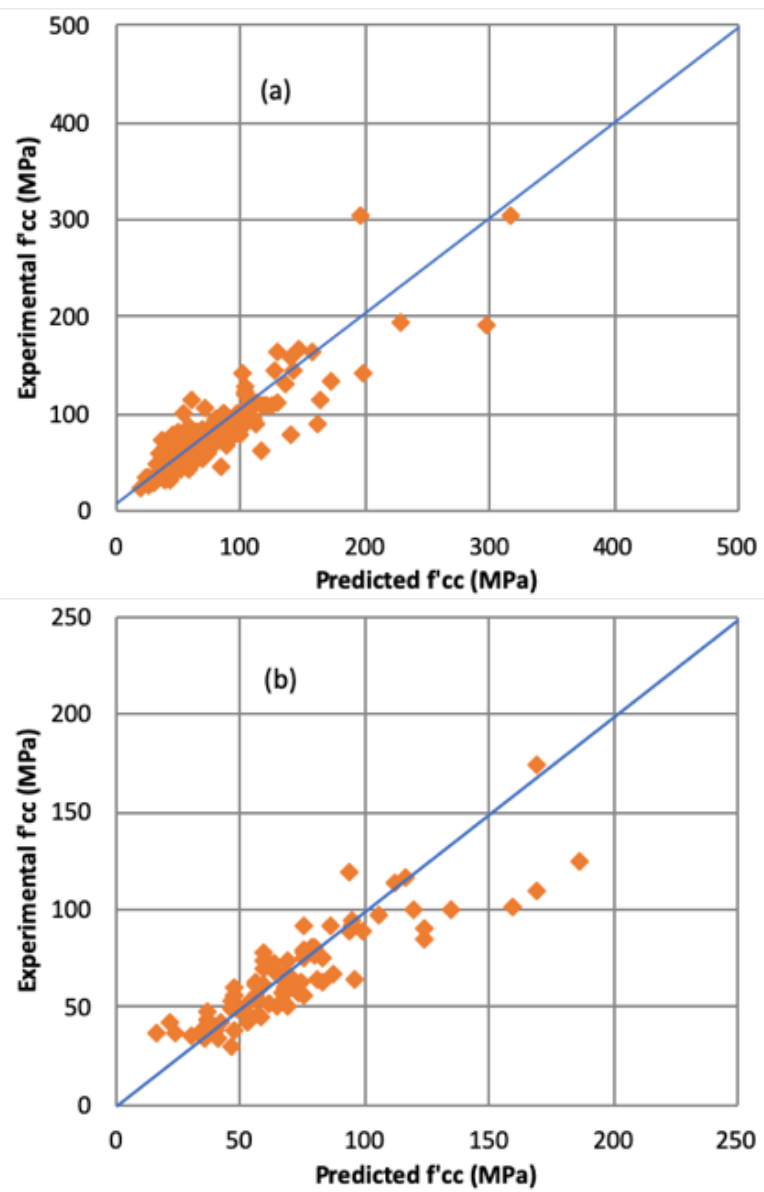

Fig. 4. Experimental vs predicted confined compressive strength using the Spoelstra \& Monti [2] model, (a) for CFRP and (b) for GFRP confinement. 

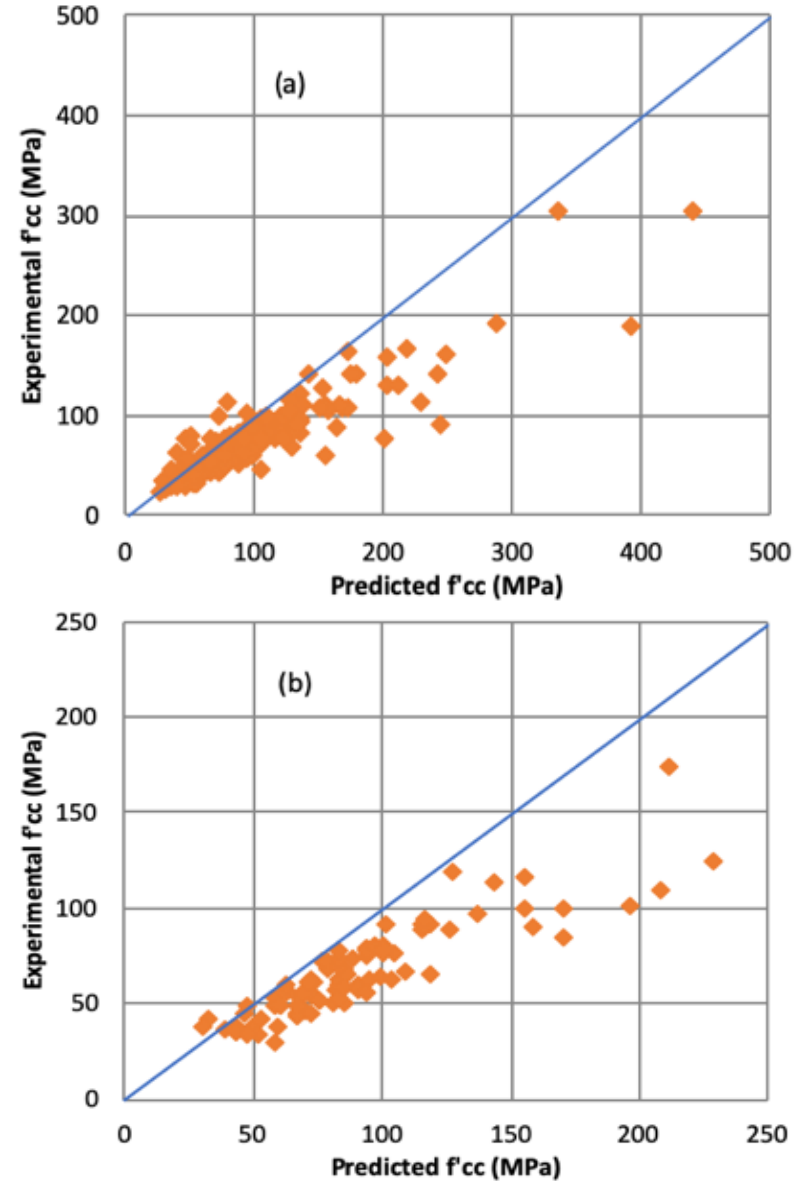

Fig. 5. Experimental vs predicted confined compressive strength using the Toutanji [5] model, (a) for CFRP and (b) for GFRP confinement
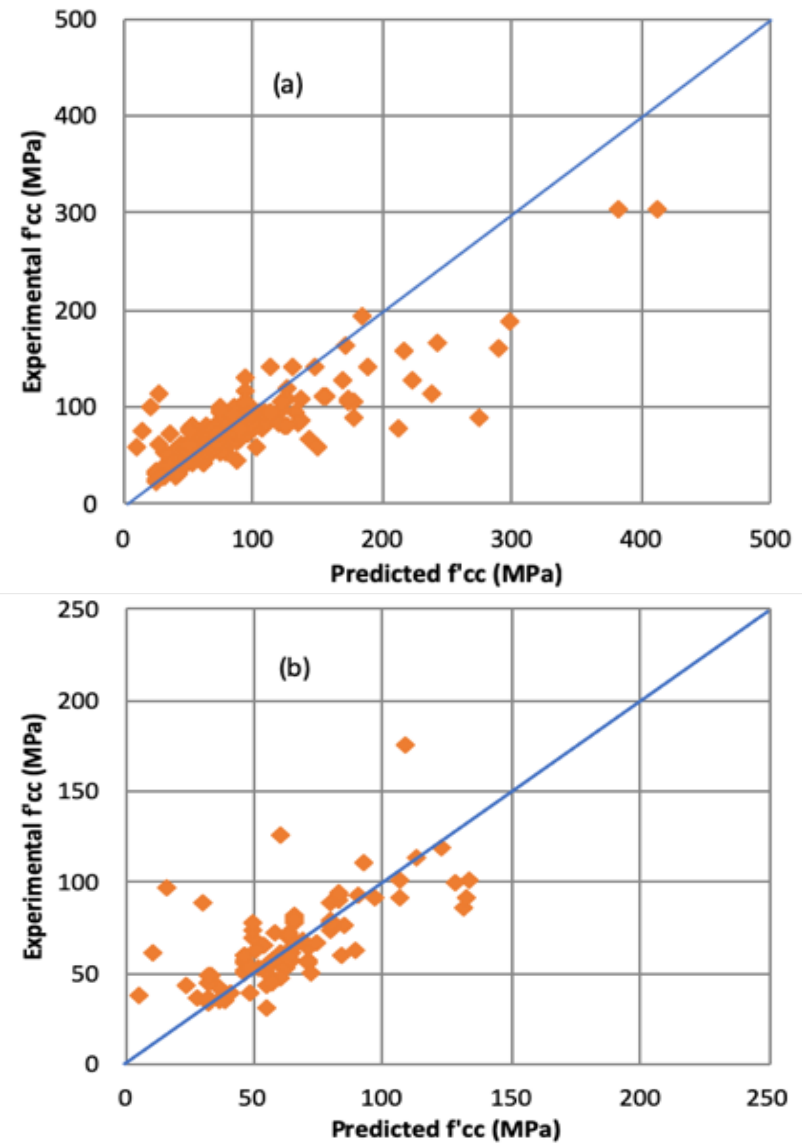

Fig. 6. Experimental vs predicted confined compressive strength using the Xiao kal Wu [18] model, (a) for CFRP and (b) for GFRP confinement.
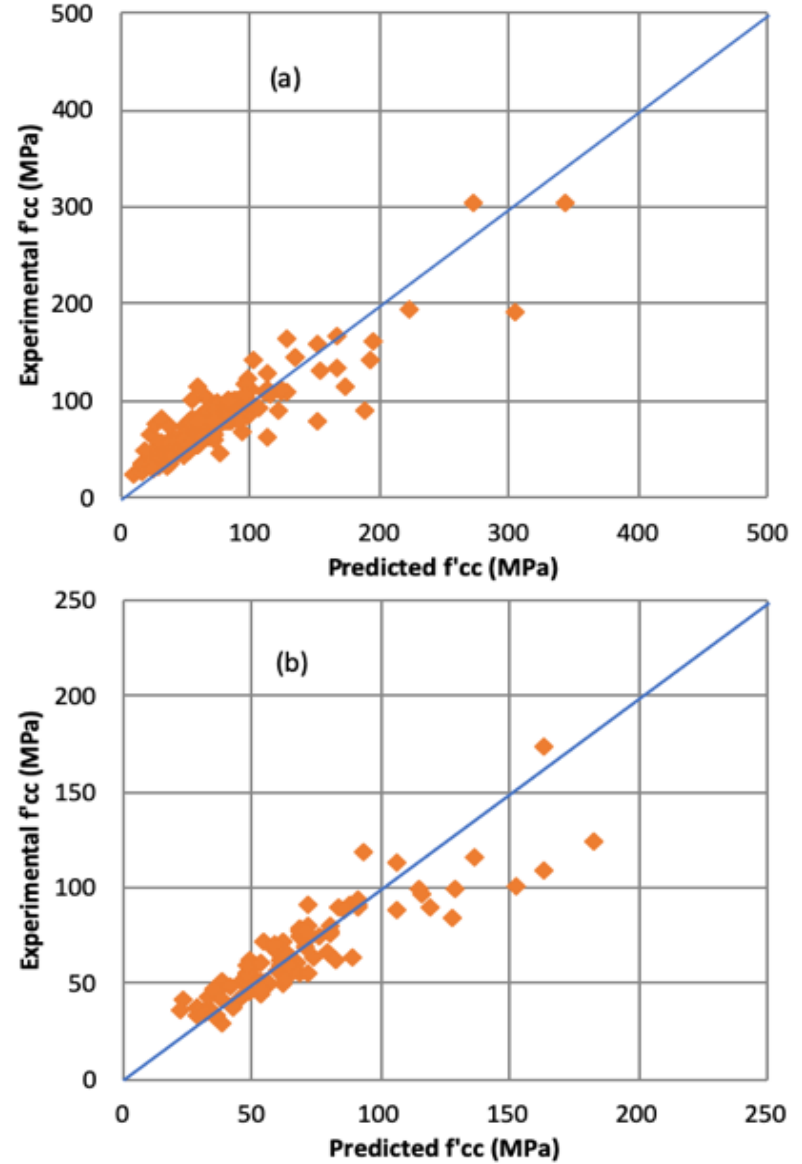

Fig. 7. Experimental vs predicted confined compressive strength using the Eurocode 2 [61] model, (a) for CFRP and (b) for GFRP confinement.
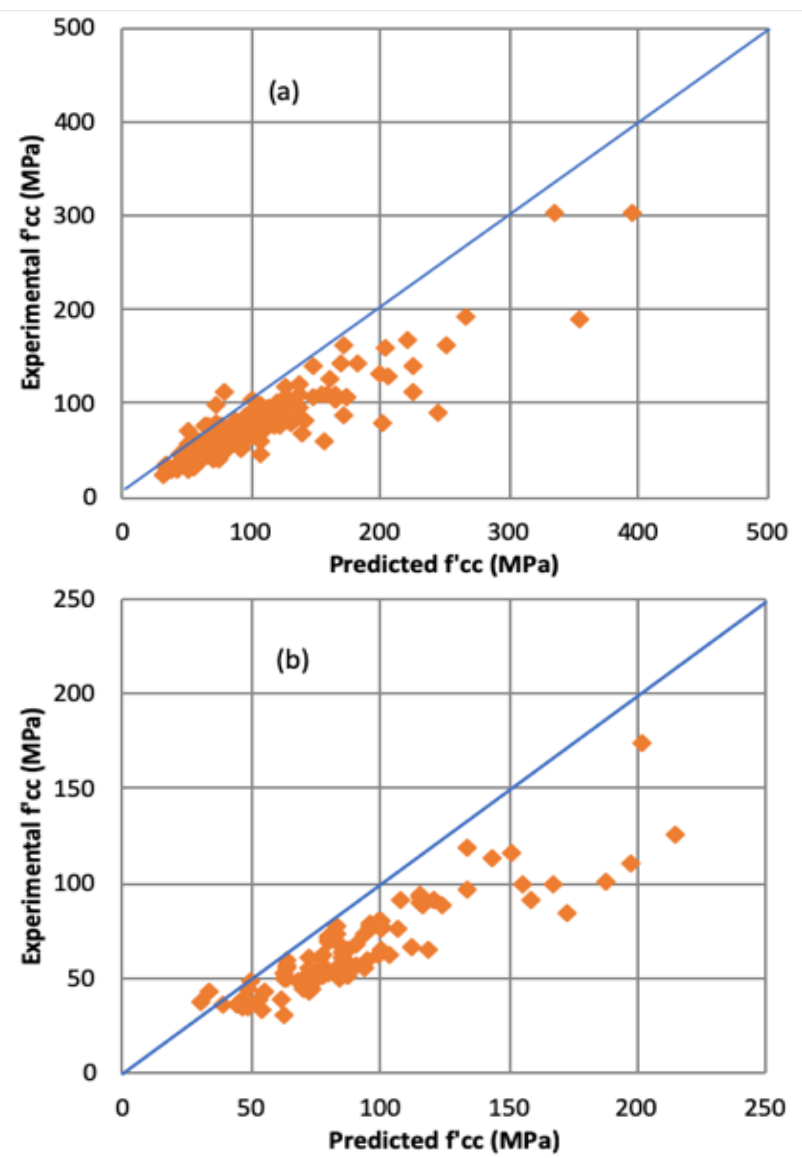

Fig. 8. Experimental vs predicted confined compressive strength using the Aire et al. [13] model, (a) for CFRP and (b) for GFRP confinement. 
Some models such as Benzaid et al. [62] (Figure 9), Csuka and Kollar [63] (Figure 10), and as expected Eurocode 2 [61] (Figure 7) exhibit an opposite performance, especially for CFRP confinement with predictions lower than the corresponding experimental strengths. For a design code, such a model behavior may be desirable, but certainly not for an analytical model.
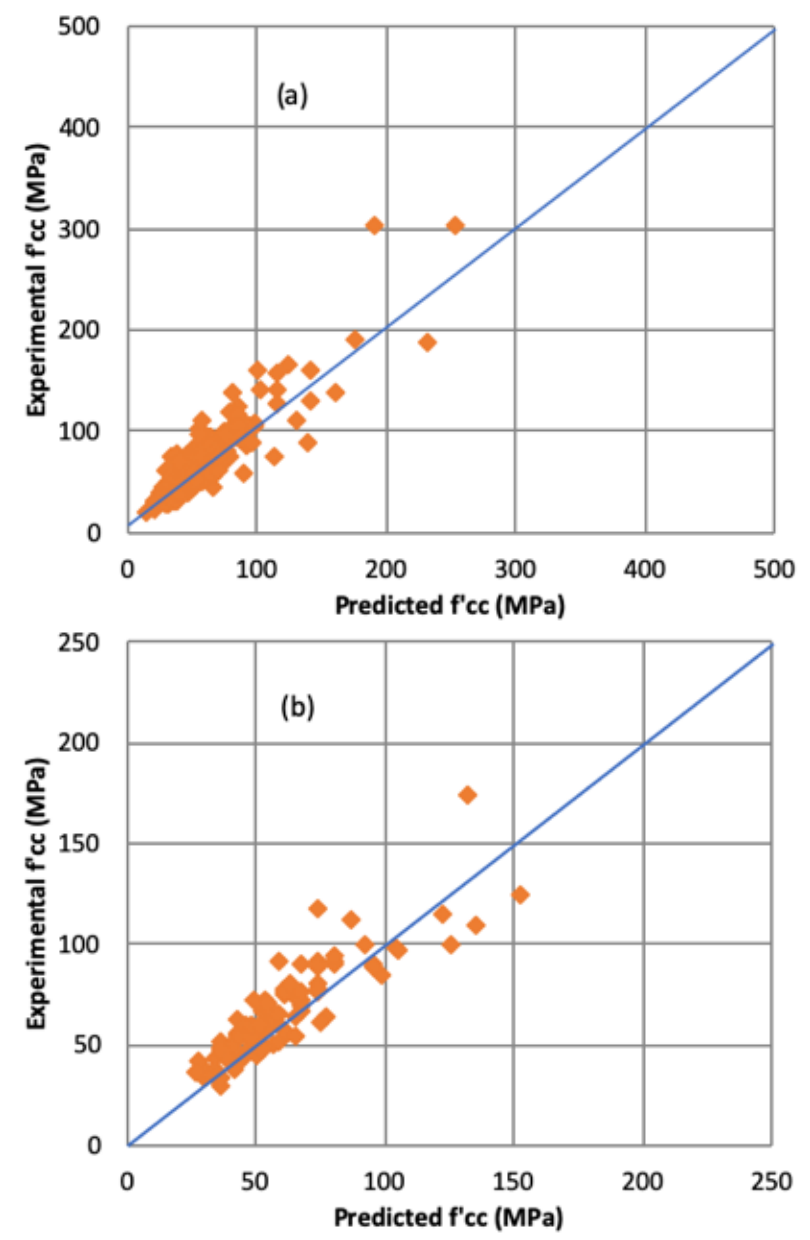

Fig. 9. Experimental vs predicted confined compressive strength using the Benzaid et al. [62] model, (a) for CFRP and (b) for GFRP confinement.

In some other cases, such as the Spoelstra \& Monti [2] model (Figure 4), the predictions of the CFRP confinement did not seem to have a distinct trend. In all cases, regardless the type of confining material, it is evident that the variability is significant, even more for specimens with large dimensions and higher confinement ratio. This may be explained by the higher representation of small specimens in the experimental sample used for calibration of the models.

Most specimens in the database had relatively small dimensions and exhibited confined strengths of less than 100MPa for both CFRP and GFRP confinement. In general, CFRP provided larger strength increases due to its higher elastic modulus and strength. However, the scatter was so great, that no statistical significance between the axial rigidity of the FRP and the confined concrete compressive strength was found.

The three newest models of Ozbakkaloglu and Lim [64] (Figure 11), Girgin [65] (Figure 12) and Touhari and Mittiche-Kettab [24] (Figure 13) seem to have visually the best performance with most of the data scattered relatively close to the diagonal, both for CFRP and GFRP confinement. Although these figures provide a indicative visual method of comparison, in order to better evaluate the efficacy of each model, quantification of the relationship between predicted and experimental concrete confined strength is deemed necessary.
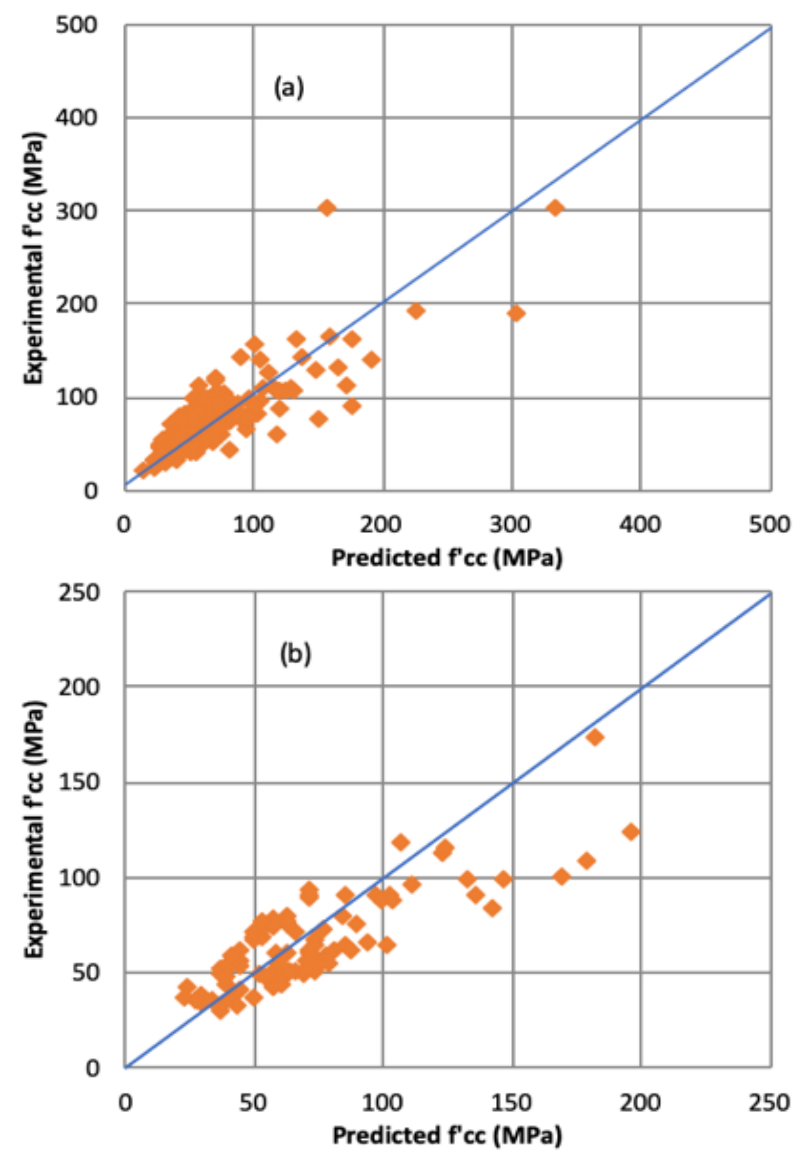

Fig. 10. Experimental vs predicted confined compressive strength using the Csuka and Kollar [63] model, (a) for CFRP and (b) for GFRP confinement.

In order to quantify the performance of the twelve models two different statistical methods were utilized. The first method quantifies the model performance in terms of average values of the ratio of experimental to predicted confined compressive strength. The second evaluation method is based on Lin's concordance coefficient which is a relatively new statistical metric, mainly used in the biomedical field, but is assumed to be the best reproducibility index (concordance correlation) $[69,70]$.

The average values of experimental confined compressive strength to predicted strength ratio for specimens confined with CFRP are shown in Figure 14. The error bars displayed in the graph indicate the calculated standard deviation. Obviously, a ratio of one with a zero standard deviation would represent a perfect analytical model exhibiting full concordance with the experimental values. However, considering concrete's strength great variability, variability associated with possible errors related to the FRP wrapping procedure, and variability of the confining material properties, a theoretically "perfect" model would be almost impossible. An examination of Figure 14 would lead to the conclusion that the models suggested by Ozbakkaloglu and Lim [64] and Girgin [65] are characterized by the best performance, since the average ratio is close to 1 and the standard deviation is less than 0.2. Besides, it can be concluded that empirical models which were developed using larger experimental datasets perform noticeably better. 
Consequently, the data indicate a positive correlation between the number of experimental data used for model calibration and the model's performance. Furthermore, it can be observed that data from experiments conducted on GFRP confined specimens are considerably fewer compared to data from CFRP confined specimens. This has an obvious negative impact on the performance of the GFRP specific models, and the prediction of the compressive strength when GFRP is used for confinement.
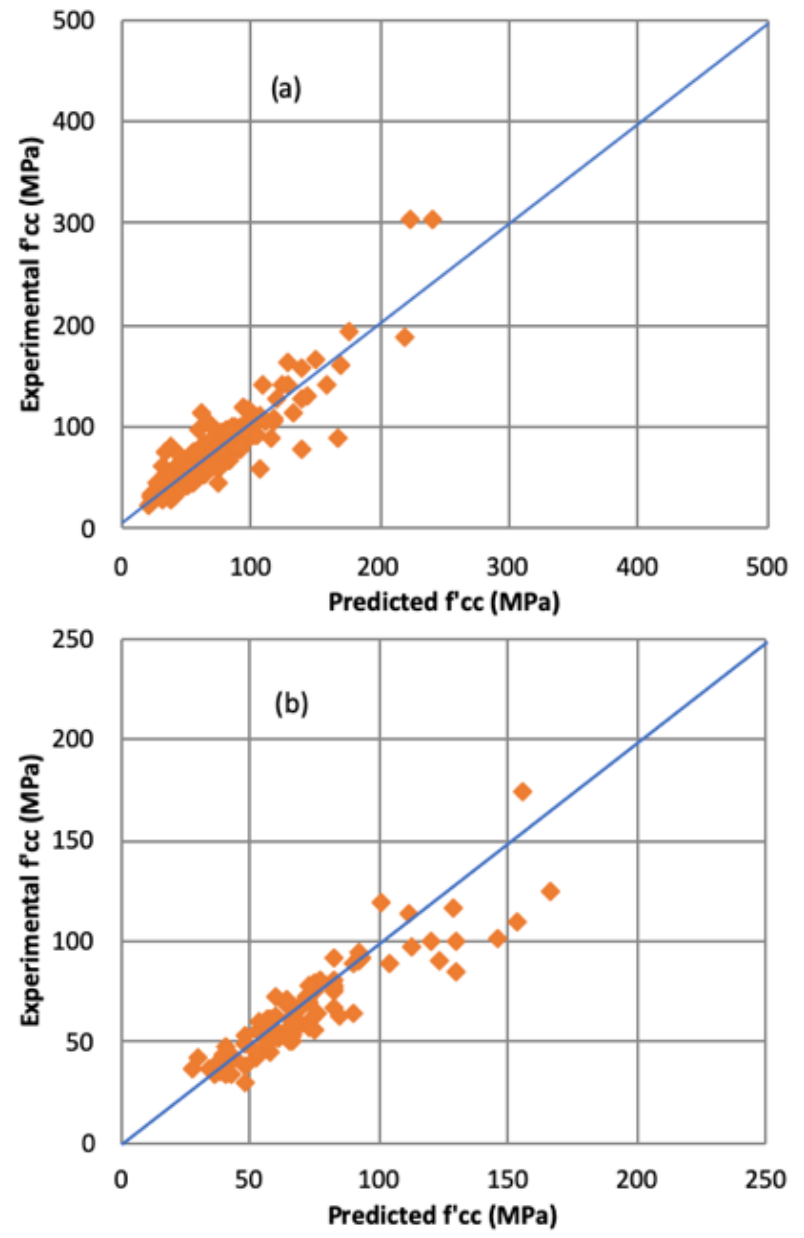

Fig. 11. Experimental vs predicted confined compressive strength using the Ozbakkaloglu and Lim [64] model, (a) for CFRP and (b) for GFRP confinement.

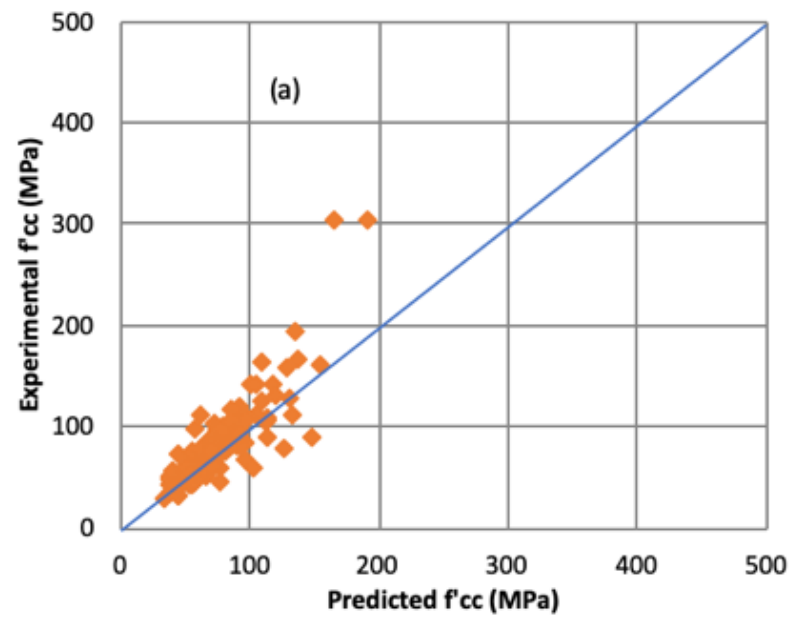

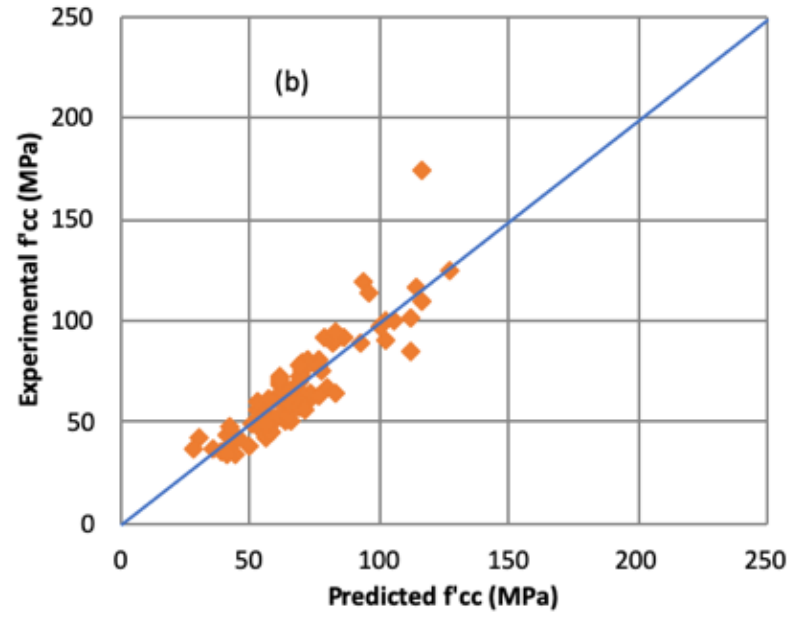

Fig. 12. Experimental vs predicted confined compressive strength using the Girgin [65] model, (a) for CFRP and (b) for GFRP confinement.
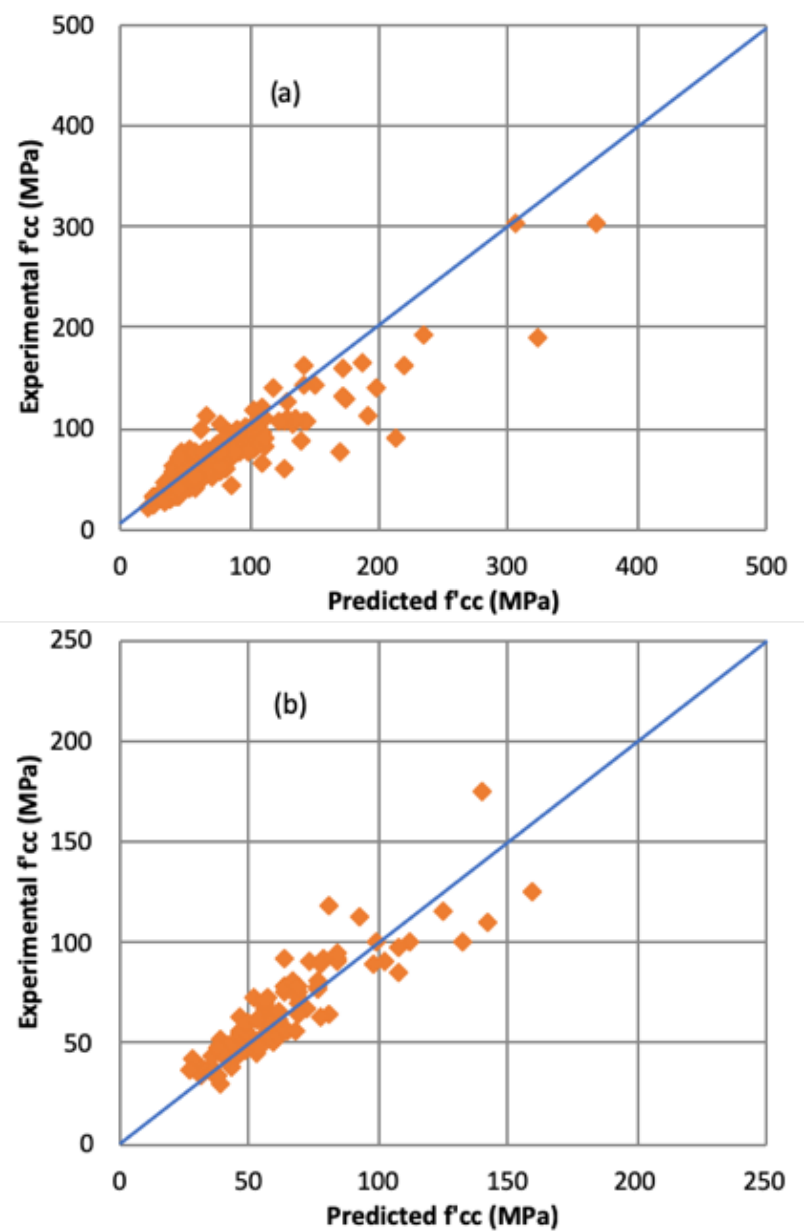

Fig. 13. Experimental vs predicted confined compressive strength using the Touhari and Mittiche-Kettab [24] model, (a) for CFRP and (b) for GFRP confinement

It is evident that Eurocode 2 [61] performs very well regardless of what type of fibers are used, using this statistical evaluation method is used. As a design code it is expected to underestimate the confined specimen's strength, which is exactly what is observed.

In order to measure the performance of each model, Lin's concordance coefficient [70] was also calculated. Lin suggested that many of the traditional validation processes are often evaluated by using the Pearson correlation coefficient, the paired t-test, the least squares analysis of slope (equal 1) and intercept (equal 0), or the coefficient of variation. He also 
mentioned that there are drawbacks to all of these, in that none alone can fully assess the desired reproducibility characteristic. Lin's coefficient is being used to evaluate the degree to which pairs of values fall on the $45^{\circ}$ line through the origin. Although not commonly used in the engineering field, it is considered to be one of the best measures of agreement between two variables in the medical field [71]. Lin's concordance coefficient, $\rho_{c}$, may take values between 1 and 1 , with the +1 value meaning full concordance and -1 full discordance. Lin's concordance coefficient, $\rho_{c}$, may be calculated as:

$$
\varrho_{c}=\rho\left(\frac{2 \sigma_{x} \sigma_{y}}{\left(\mu_{\chi}-\mu_{y}\right)^{2}+\sigma_{x}^{2}+\sigma_{y}^{2}}\right)=\rho \cdot C_{\beta}
$$

where: $\rho$ is Pearson's correlation coefficient, $\mu_{x}$ and $\mu_{y}$, the mean values of the two variables and $\sigma_{\chi}, \sigma_{y}$, the standard deviation of the two variables. Lin's concordance coefficient, $\rho_{\mathrm{c}}$, measures both precision, $\rho$, and accuracy, $C_{\beta}$. Where $C_{\beta}$ is a bias correction factor, a measure of how far a line of best fit (or the line of perfect concordance) is from a line at 45-degree angle through the origin.

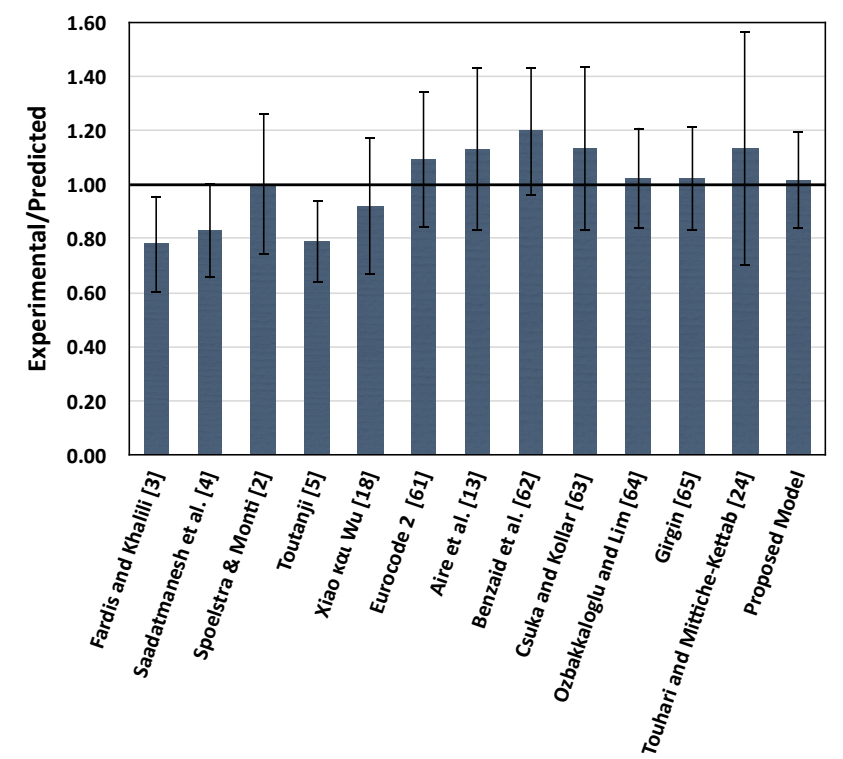

Fig. 14. Average $f_{c c, e x p} / f_{c c, p r e}$ for each model for CFRP confined specimens

The model's performance using Lin's concordance coefficient is illustrated in a bar chart (Figure 16) and the corresponding values are displayed in Table 1. More specifically, Figure 15 shows three bars for each model representing Lin's coefficients, $\rho_{c}$, in the case of CFRP confinement, GFRP confinement and finally for all specimens. For most of the models the calculated coefficients for GFRP confinement are considerably lower than of CFRP confinement. The best performing models [24, 65] have a Lin's coefficient of 0.78 , while the lowest value is 0.45 , which indicates a poor concordance. The highest coefficient for CFRP confinement was equal to 0.85 for the model of Spoelstra and Monti [2], while the lowest value was found equal to 0.69 for Fardis and Khalili [3]. Provided that concrete is a material that exhibits substantial variability in terms of compressive strength, we could consider that values of Lin's coefficient higher than 0.8 to correspond to models with very good performance. This is in agreement with the 0.8 threshold recommended by Altman [69]. It is important to note that the design equations suggested by Eurocode provide excellent results, with a Lin's coefficient of 0.78 for CFRP confinement and also 0.78 for the full database. In terms of GFRP confinement, Eurocode performs very well with a coefficient of 0.73. Only three out of the twelve models have concordance coefficients higher than 0.8 for CFRP confinement. These are the models proposed by Ozbakkaloglou and Lim [64], Spoelstra \& Monti [2], and Benzaid et al. [62]. A study of Table 1., that provides all statistical values, along with Figure 16. lead to the conclusion that Lin's coefficients for all specimens are almost identical to the coefficients calculated for CFRP confinement. This can be explained by the significant larger number of CFRP confined compared to GFRP confined specimens.

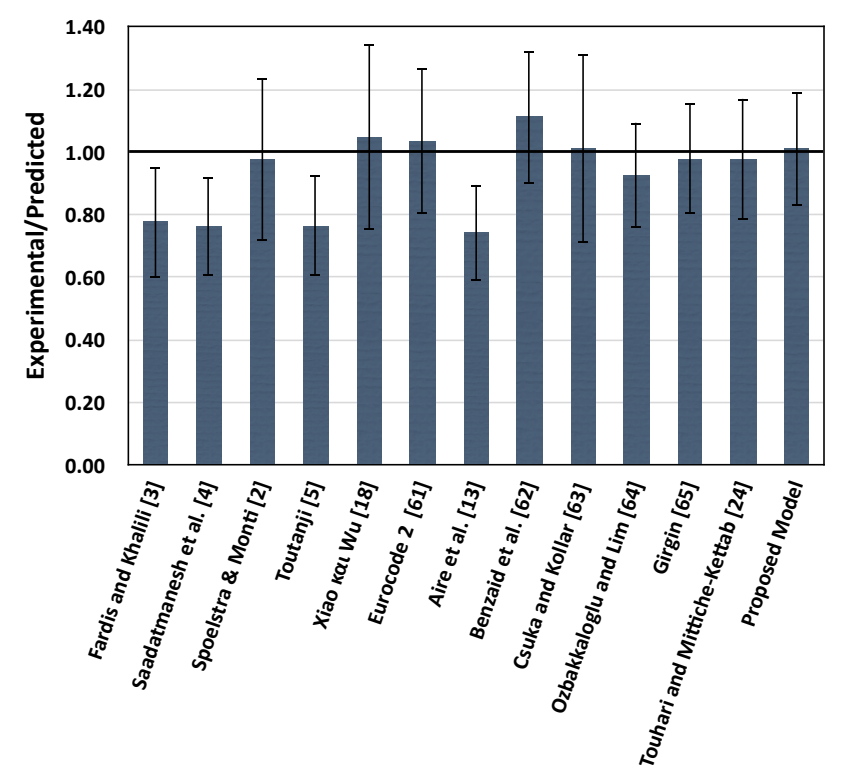

Fig. 15. Average $f_{c c, e x p} / f_{c c, p r e}$ for each model for GFRP confined specimens

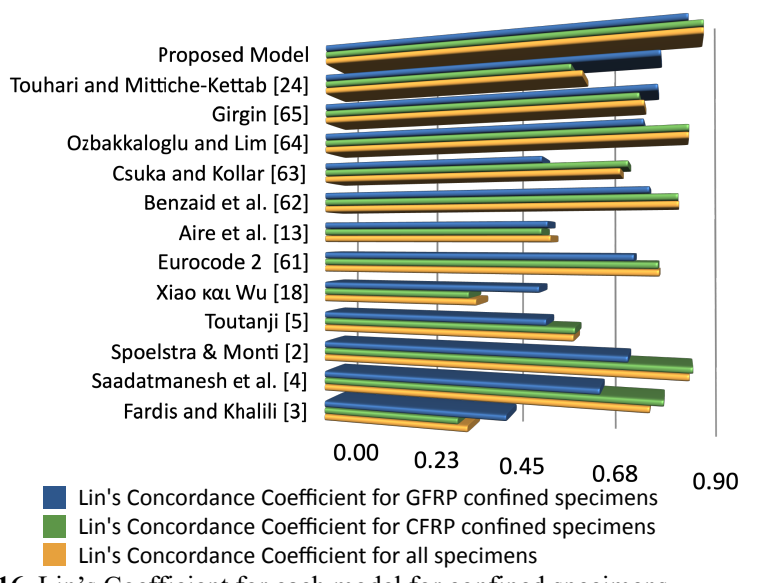

Fig. 16. Lin's Coefficient for each model for confined specimens 
Table 1. Performance quantification for each compressive strength model

\begin{tabular}{|c|c|c|c|c|c|c|c|c|c|}
\hline $\begin{array}{l}\text { Theoretical models for } \\
\text { the prediction of the } \\
\text { confined compressive } \\
\left.\text { strength (f' }{ }_{c c}\right)\end{array}$ & $\begin{array}{c}\text { Lin's } \\
\text { Concorda } \\
\text { nce } \\
\text { Coefficie } \\
\text { nt for all } \\
\text { specimen } \\
\text { s }\end{array}$ & $\begin{array}{c}\text { Mean } \\
\text { value of } \\
\text { the ratio: } \\
{\text { f'cc,exp } / \mathbf{f}^{\prime} \text { cc }} \\
\text {,pred for } \\
\text { all } \\
\text { specimen } \\
\text { s }\end{array}$ & $\begin{array}{c}\text { Standar } \\
\text { d } \\
\text { deviation } \\
\text { of the } \\
\text { ratio: } \\
\text { f'cc,exp } / \mathbf{f}^{\prime} \text { cc } \\
\text {,pred for } \\
\text { all } \\
\text { confined } \\
\text { specimen } \\
\text { s }\end{array}$ & $\begin{array}{c}\text { Lin's } \\
\text { Concorda } \\
\text { nce } \\
\text { Coefficie } \\
\text { nt for } \\
\text { CFRP } \\
\text { confined } \\
\text { specimen } \\
\text { s }\end{array}$ & $\begin{array}{c}\text { Mean } \\
\text { value of } \\
\text { the ratio: } \\
\text { f'cc,exp/f'cc } \\
\text {,pred for } \\
\text { CFRP } \\
\text { confined } \\
\text { specimen } \\
\text { s }\end{array}$ & $\begin{array}{c}\text { Standar } \\
\text { d } \\
\text { deviation } \\
\text { of the } \\
\text { ratio: } \\
\text { f'cc,exp/f'cc } \\
\text {,pred for } \\
\text { CFRP } \\
\text { confined } \\
\text { specimen } \\
\text { s }\end{array}$ & $\begin{array}{c}\text { Lin's } \\
\text { Concorda } \\
\text { nce } \\
\text { Coefficie } \\
\text { nt for } \\
\text { GFRP } \\
\text { confined } \\
\text { specimen } \\
\text { s }\end{array}$ & $\begin{array}{c}\text { Mean } \\
\text { value of } \\
\text { the ratio: } \\
\text { f'cc,exp/f'cc } \\
\text {,pred for } \\
\text { GFRP } \\
\text { confined } \\
\text { specimen } \\
\text { s }\end{array}$ & $\begin{array}{c}\text { Standar } \\
\text { d } \\
\text { deviation } \\
\text { of the } \\
\text { ratio: } \\
\text { f'cc,exp/f'cc } \\
\text {,pred for } \\
\text { GFRP } \\
\text { confined } \\
\text { specimen } \\
\text { s }\end{array}$ \\
\hline Fardis and Khalili [3] & 0.36 & 0.78 & 0.18 & 0.34 & 0.78 & 0.18 & 0.45 & 0.78 & 0.18 \\
\hline Saadatmanesh et al. [4] & 0.76 & 0.81 & 0.17 & 0.79 & 0.83 & 0.17 & 0.66 & 0.77 & 0.16 \\
\hline Spoelstra \& Monti [2] & 0.84 & 0.99 & 0.27 & 0.85 & 1.00 & 0.26 & 0.72 & 0.99 & 0.29 \\
\hline Toutanji [5] & 0.60 & 0.78 & 0.15 & 0.60 & 0.79 & 0.15 & 0.54 & 0.77 & 0.17 \\
\hline 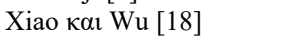 & 0.38 & 0.99 & 0.45 & 0.36 & 0.92 & 0.25 & 0.52 & 1.02 & 0.27 \\
\hline Eurocode 2 [61] & 0.78 & 1.07 & 0.25 & 0.78 & 1.09 & 0.25 & 0.73 & 1.05 & 0.24 \\
\hline Aire et al. [13] & 0.55 & 0.75 & 0.15 & 0.53 & 1.13 & 0.30 & 0.54 & 0.74 & 0.16 \\
\hline Benzaid et al. [62] & 0.82 & 1.20 & 0.24 & 0.82 & 1.20 & 0.24 & 0.76 & 1.12 & 0.21 \\
\hline Csuka and Kollar [63] & 0.70 & 1.13 & 0.30 & 0.72 & 1.13 & 0.30 & 0.53 & 1.02 & 0.31 \\
\hline $\begin{array}{l}\text { Ozbakkaloglu and Lim } \\
\text { [64] }\end{array}$ & 0.84 & 0.99 & 0.19 & 0.84 & 1.02 & 0.19 & 0.75 & 0.93 & 0.17 \\
\hline Girgin [65] & 0.75 & 1.01 & 0.19 & 0.74 & 1.02 & 0.19 & 0.78 & 0.97 & 0.17 \\
\hline $\begin{array}{l}\text { Touhari and Mittiche- } \\
\text { Kettab [24] }\end{array}$ & 0.62 & 1.09 & 0.39 & 0.60 & 1.13 & 0.43 & 0.78 & 0.97 & 0.19 \\
\hline Proposed Model & 0.87 & 1.00 & 0.18 & 0.87 & 1.00 & 0.18 & 0.84 & 1.01 & 0.18 \\
\hline
\end{tabular}

Ozbakkaloglou and Lim's [64] and Spoelstra \& Monti's [2] models perform equally well regardless of statistical analysis type. On the contrary the model proposed by Benzaid and colleagues [62], which was among the three best performing models, and exhibited an overall Lin's coefficient of 0.82 does not perform equally well when the mean value and standard variation of the experimental over predicted compressive stress was used to quantify performance. So, although its concordance coefficient was excellent, the experimental compressive stress values were considerable higher than the predicted compressive stress, providing a mean ratio of 1.2 with a corresponding standard deviation of 0.24 .

The reason that two different metrics are used in this study to evaluate model's ability to correctly predict concrete compressive confined strength was to perform a better validation with less possible statistical errors. Other than the model proposed by Spoelstra \& Monti [2] relatively older models seem to not perform as well, exhibiting low Lin's coefficients.

According to the calculated Lin's concordance coefficients many model's performance was better when CFRP was used. For example models suggested by Spoelstra and Monti [2], and Ozbakkaloglou and Lim [64] had Lin's coefficients 0.72 and 0.75 respectively when GFRP was used for confinement. This is a considerable drop from the coefficients for CFRP and combined specimens. This difference shows that more tests are necessary in order to better predict the performance of GFRP confinement.

The two best performing models are quite different. Spoelstra and Monti [2], suggested a simple single equation model, while Ozbakkaloglou and Lim's [64] newer model suggests the use of a much more complicated method. Furthermore, while the former used a relatively small experimental database with limited unconfined concrete strength range, the latter used a significantly more extensive database.

In order to use our large experimental database to develop a simple equation similar to that suggested by Touhari and Mittiche-Kettab [24] with a good efficacy, the $f^{\prime}{ }_{c c} / f^{\prime}{ }_{c o}$ ratio was plotted versus the $f_{l} / f^{\prime}$ co. This is illustrated in Figures 18 (a) and (b), which correspond to cylinders with CFRP and GFRP confinement, respectively. A regression analysis resulted in an equation that had the general form:

$$
\frac{\mathrm{f}_{\mathrm{cc}}}{\mathrm{f}_{\mathrm{co}}}=\left(1+\mathrm{a} *\left(\frac{\mathrm{f}_{\mathrm{I}}}{\mathrm{f}_{\mathrm{co}}}\right)^{b}\right)
$$

The main idea was to develop one simple equation that may be used to determine the confined compressive strength regardless of confining material. Thus, based on the graph shown in Figure 18(a) a relationship between the variables of the graph was obtained using regression analysis. Thus, Eq. 39 was derived for CFRP confined specimens, with a coefficient of determination $\mathrm{R}^{2}=0.708$ :

$$
\mathrm{f}^{\prime}{ }_{\mathrm{cc}}=\mathrm{f}^{\prime}{ }_{\mathrm{co}} *\left\{2.1 *\left(\frac{\mathrm{f}_{\mathrm{l}}}{\mathrm{f}_{\mathrm{co}}}\right)^{0.86}+1.0\right\}
$$

Although a different equation could have been derived from the GRFP confined specimens it was decided to use just one general equation (Eq.40) to describe the relationship between $f^{\prime}{ }_{c c} / f^{\prime}{ }_{c o}$ and $f_{l} / f^{\prime}{ }_{c o}$. Eq 40 for GFRP confined specimens exhibited a coefficient of determination of $\mathrm{R}^{2}=0.678$ (Figure 18(b)). It should be noted that a higher coefficient of determination could have been obtained from another equation for GFRP but as mentioned previously the author believes that a one-equation model offers a more valuable design tool.

The performance of the proposed model can be seen in Figures 14 to 17 , compared to the performance of the 12 examined models. It is evident that the proposed equation performs very well regardless of the confining material type, both in terms of average ratio (it is almost one with a standard deviation of 0.18 ), and Lin coefficient. More specifically, the proposed model's Lin coefficient is 0.87 , which is greater than the highest Lin's coefficient $(0.84)$, that of Ozbakkaloglou and Lim [64] and that of Spoelstra \& Monti $[2]$. 


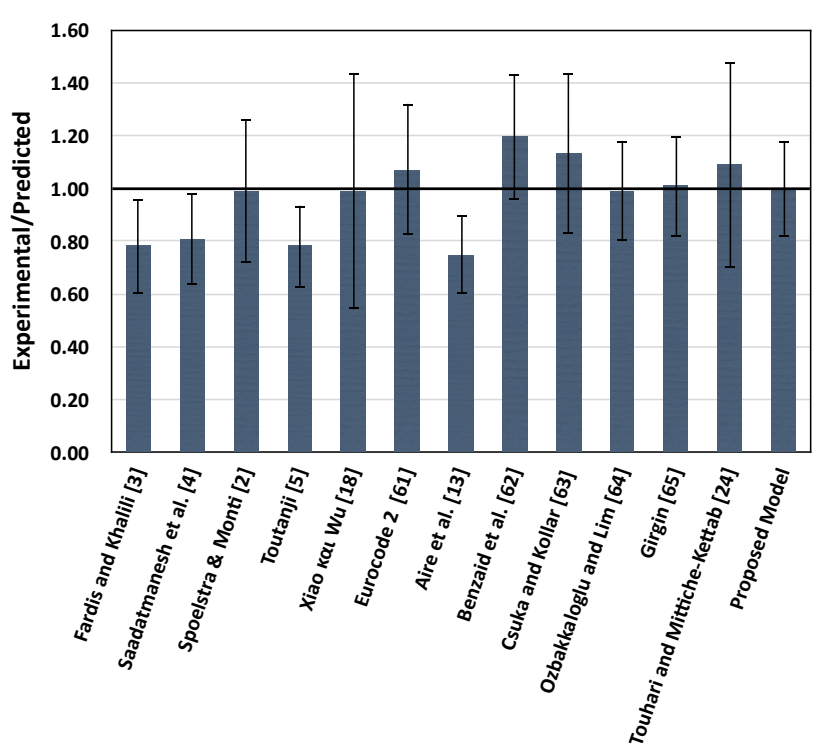

Fig. 17. Average $f_{c c, e x p} / f_{c c, p r e}$ for each model for all confined specimens
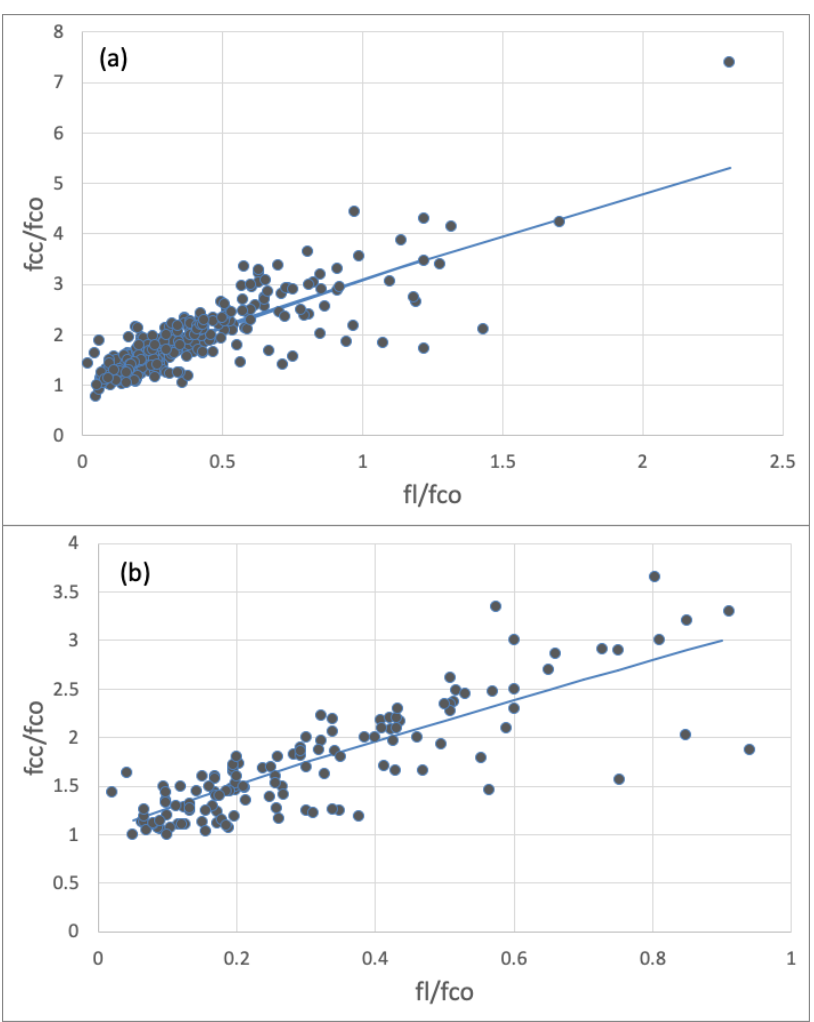

Fig. 18. $k_{\text {eff }}$ vs $f_{l} / f_{\text {co }}$ values and linear correlation for: (a) CFRP confinement, and (b) GFRP confinement

In terms of average ratio and GFRP confinement, the proposed equation provides the best performing model with an average ratio of 1.01 and a standard deviation of just 0.18
(Figure 15). Moreover, its performance was also the best when examined via Lin's coefficient. More specifically, Lin's coefficient for GFRP confinement was 0.84 and was the only equation that exhibited value higher than 0.8 (proving excellent concordance) (Figure 16). The second highest coefficient of 0.78 was recorded for the models suggested by Touhari and Girgin. Therefore, it is evident that one simple equation can provide excellent confined concrete strength predictions, regardless of the confining material used.

\section{Conclusions}

Based on the findings of this comparative review study the following conclusions can be drawn:

- The size of experimental database affects significantly the performance of the analytical models, which use empirical factors.

- FRP rupture determines the fracture of the specimens. However, it was observed that the recorded ultimate FRP strain was significantly lower than the theoretically maximum FRP strain obtained by uniaxial coupon tests.

- The majority of the tested concrete specimens were confined using CFRP, while one third of the total specimens were confined using GFRP.

- There is a need for confined specimens tests with both low and high unconfined concrete compressive strength. Also, the effect of specimen size should be studied.

- Eurocode provides a quite safe design tool for confined concrete structural elements.

- In terms of Lin's concordance correlation the model suggested by Spoelstra and Monti [2], along with the ones described by Ozbakkaloglou and Lim [64], and Benzaid et al. [62] where the most effective.

- The proposed model has shown that although one would expect that more elaborate models would perform better than simple one-equation models this is not necessarily the case.

- The proposed equation provides a very simple and the most effective way to predict the confined strength of concrete when either CFRP or GFPR is used for confinement. It may also be used with GFRP confinement with very good effectiveness.

\section{Acknowledgments}

The author would like to thank Ms Sotiria Papaisidorou for her assistance in the creation of the experimental database.

This is an Open Access article distributed under the terms of the Creative Commons Attribution License

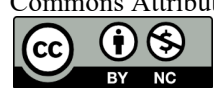

\section{References}

1. H.A. Toutanji, Stress-strain characteristics of concrete columns externally confined with advanced fiber composite sheets, Aci Materials Journal 96(3) (1999) 397-404.

2. M.R.M. Spoelstra, G., FRP-confined concrete model, ASCE Journal of Composites in Construction 3 (1999) 143-150.

3. M.N.K. Fardis, H.H., Concrete encased in fiber glass reinforced plastic, Aci Struct J 78 (1981) 440-445.
4. H. Saadatmanesh, M.R. Ehsani, M.W. Li, Strength and Ductility of Concrete Columns Externally Reinforced with Fiber-Composite Straps, Aci Struct J 91(4) (1994) 434-447.

5. H. Toutanji, Design equations for concrete columns confined with hybrid composite materials, Adv Compos Mater 10(2-3) (2001) 127138.

6. EU, Eurocode 8: Design of structures for earthquake resistance - Part 3, EN 1998-3, European Union, 2005. 
7. I. Howie, V.M. Karbhari, Effect of Tow Sheet Composite Wrap Architecture on Strengthening of Concrete Due to Confinement .1. Experimental Studies, Journal of Reinforced Plastics and Composites 14(9) (1995) 1008-1030.

8. T.G.S. Harmon, K. T. , Advanced composite confinement of concrete., in: C.S.f.C. Engineering (Ed.) Proc., Int. Conf. on Advanced Composite Materials in Bridges and Structures, 1992, pp. 299-306.

9. B.K. Purba, A.A. Mufti, Investigation of the behavior of circular concrete columns reinforced with carbon fiber reinforced polymer (GFRP) jackets, Canadian Journal of Civil Engineering 26(5) (1999) 590-596.

10. J.F. Berthet, E. Ferrier, P. Hamelin, Compressive behavior of concrete externally confined by composite jackets. Part A: experimental study, Constr Build Mater 19(3) (2005) 223-232.

11. V.S. Silva, J., Strengthening of axially loaded concrete cylinders by surface composites., Composites in Constructions, Proceedings of the International Conference, 2001, pp. 257-262.

12. L. Lam, J.G. Teng, Ultimate condition of fiber reinforced polymerconfined concrete, J Compos Constr 8(6) (2004) 539-548.

13. C. Aire, R. Gettu, J.R. Casas, S. Marques, D. Marques, Concrete laterally confined with fibre-reinforced polymers (FRP): experimental study and theoretical model, Materiales De Construccion 60(297) (2010) 19-31.

14. P.F. Marques, C. Chastre, Performance analysis of load-strain models for circular columns confined with FRP composites, Compos Struct 94(11) (2012) 3115-3131.

15. V. Tamuzs, R. Tepfers, C.S. You, T. Rousakis, I. Repelis, V. Skruls, U. Vilks, Behavior of concrete cylinders confined by carboncomposite tapes and prestressed yarns - 1. Experimental data, Mechanics of Composite Materials 42(1) (2006) 13-32.

16. I.A.E.M. Shehata, L.A.V. Carneiro, L.C.D. Shehata, Strength of short concrete columns confined with CFRP sheets, Mater Struct 35(245) (2002) 50-58.

17. Y. Xiao, H. Wu, Compressive behavior of concrete confined by various types of FRP composite jackets, Journal of Reinforced Plastics and Composites 22(13) (2003) 1187-1201.

18. Y. Xiao, H. Wu, Compressive behavior of concrete confined by carbon fiber composite jackets, Journal of Materials in Civil Engineering 12(2) (2000) 139-146.

19. M.N. Youssef, M.Q. Feng, A.S. Mosallam, Stress-strain model for concrete confined by FRP composites, Compos Part B-Eng 38(5-6) (2007) 614-628.

20. M. Youssef, Stress strain model for concrete confined by FRP composites, niversity of California, Irvine, Irvine, Calif, USA, 2003.

21. T.H. Almusallam, Behavior of normal and high-strength concrete cylinders confined with E-glass/epoxy composite laminates, Compos Part B-Eng 38(5-6) (2007) 629-639.

22. R. Abbasnia, R. Ahmadi, H. Ziaadiny, Effect of confinement level, aspect ratio and concrete strength on the cyclic stress-strain behavior of FRP-confined concrete prisms, Compos Part B-Eng 43(2) (2012) 825-831.

23. S. Bullo, Experimental Study of the Effects of the Ultimate Strain of Fiber Reinforced Plastic Jackets on the Behavior of Confined Concrete, Proceedings of the International Conference on Composites in Construction, Cosenza, Italy, 2003, pp. 465-470.

24. M. Touhari, R. Mitiche-Kettab, Behaviour of FRP Confined Concrete Cylinders: Experimental Investigation and Strength Model, Period Polytech-Civ 60(4) (2016) 647-660.

25. S.A. Carey, K.A. Harries, Axial behavior and modeling of confined small-, medium-, and large-scale circular sections with carbon fiberreinforced polymer jackets, Aci Struct J 102(4) (2005) 596-604.

26. C. Chastre, M.A.G. Silva, Monotonic axial behavior and modelling of RC circular columns confined with CFRP, Eng Struct 32(8) (2010) 2268-2277.

27. H. Bouchelaghem, A. Bezazi, F. Scarpa, Compressive behaviour of concrete cylindrical FRP-confined columns subjected to a new sequential loading technique, Compos Part B-Eng 42(7) (2011) 1987-1993.

28. M. Demers, K.W. Neale, Confinement of reinforced concrete columns with fibre-reinforced composite sheets - an experimental study, Canadian Journal of Civil Engineering 26(2) (1999) 226-241.

29. M. Fernandez-Canovas, M.N. Gonzalez-Garcia, J.A. Pinero, A. Cobo, Compressive strength behaviour of low- and medium-strength concrete specimens confined with carbon fibres in defective implementation conditions: an experimental study, Materiales De Construccion 66(324) (2016).
30. C. Cui, S.A. Sheikh, Experimental Study of Normal- and HighStrength Concrete Confined with Fiber-Reinforced Polymers, J Compos Constr 14(5) (2010) 553-561.

31. S.P.C. Marques, D.C.S.C. Marques, J.L. da Silva, M.A.A Cavalcante, Model for analysis of short columns of concrete confined by fiber-reinforced polymer, J Compos Constr 8(4) (2004) $332-340$

32. A. Ilki, N. Kumbasar, V. Koc, Low strength concrete members externally confined with FRP sheets, Structural Engineering and Mechanics 18(2) (2004) 167-194.

33. A. Ilki, N. Kumbasar, Behavior of damaged and undamaged concrete strengthened by carbon fiber composite sheets, Structural Engineering and Mechanics 13(1) (2002) 75-90.

34. S. Kshirsagar, R.A. Lopez-Anido, R.K. Gupta, Environmental aging of fiber-reinforced polymer-wrapped concrete cylinders, Aci Materials Journal 97(6) (2000) 703-712.

35. T. Jiang, J.G. Teng, Analysis-oriented stress-strain models for FRPconfined concrete, Eng Struct 29(11) (2007) 2968-2986.

36. K.A. Harries, G. Kharel, Experimental investigation of the behavior of variably confined concrete, Cement and Concrete Research 33(6) (2003) 873-880.

37. S. Kono, M. Inazumi, T. Kaku, Evaluation of confining effects of CFRP sheets on reinforced concrete members, 2nd International Conference on Composites in Infrastructure, Tucson, Arizona, USA, 1998, pp. 343-355.

38. L. Lam, J.G. Teng, C.H. Cheung, Y. Xiao, FRP-confined concrete under axial cyclic compression, Cement and Concrete Composites 28(10) (2006) 949-958.

39. S. Matthys, H. Toutanji, L. Taerwe, Stress-strain behavior of largescale circular columns confined with FRP composites, Journal of Structural Engineering 132(1) (2006) 123-133.

40. H. Toutanji, M. Han, J. Gilbert, S. Matthys, Behavior of Large-Scale Rectangular Columns Confined with FRP Composites, J Compos Constr 14(1) (2010) 62-71.

41. M. Shahawy, A. Mirmiran, T. Beitelman, Tests and modeling of carbon-wrapped concrete columns, Compos Part B-Eng 31(6-7) (2000) 471-480.

42. F. Micelli, R. Modarelli, Experimental and analytical study on properties affecting the behaviour of FRP-confined concrete, Compos Part B-Eng 45(1) (2013) 1420-1431.

43. S. Pessiki, K.A. Harries, J.T. Kestner, R. Sause, J.M. Ricles, Axial behavior of reinforced concrete columns confined with FRP jackets, J Compos Constr 5(4) (2001) 237-245.

44. P.D. Li, Y.F. Wu, R. Gravina, Cyclic response of FRP-confined concrete with post-peak strain softening behavior, Constr Build Mater 123 (2016) 814-828.

45. M.A.G. Silva, C.C. Rodrigues, Size and relative stiffness effects on compressive failure of concrete columns wrapped with glass FRP, Journal of Materials in Civil Engineering 18(3) (2006) 334-342.

46. R. Benzaid, H.A. Mesbah, The confinement of concrete in compression using CFRP composites - effective design equations, Journal of Civil Engineering and Management 20(5) (2014) 632-648.

47. H. Toutanji, Y. Deng, Performance of concrete columns strengthened with fiber reinforced polymer composite sheets, Adv Compos Mater 10(2-3) (2001) 159-168.

48. Z.Y. Wang, D.Y. Wang, S.T. Smith, D.G. Lu, Experimental testing and analytical modeling of CFRP-confined large circular RC columns subjected to cyclic axial compression, Eng Struct 40 (2012) 64-74.

49. A. Ilki, O. Peker, E. Karamuk, C. Demir, N. Kumbasar, FRP retrofit of low and medium strength circular and rectangular reinforced concrete columns, Journal of Materials in Civil Engineering 20(2) (2008) 169-188.

50. W. Perceka, W.C. Liao, Y.D. Wang, High Strength Concrete Columns under Axial Compression Load: Hybrid Confinement Efficiency of High Strength Transverse Reinforcement and Steel Fibers, Materials 9(4) (2016).

51. Y.F.F. Li, T.S.; Chern, C.C., A Constitutive Model for Concrete Cylinder Confined by Steel Reinforcement and Carbon Fibre Sheet, Pacific conference on earthquake engineering, Christchurch, New Zealand 2003, pp. 1-18.

52. T.C. Rousakis, A.I. Karabinis, P.D. Kiousis, FRP-confined concrete members: Axial compression experiments and plasticity modelling, Eng Struct 29(7) (2007) 1343-1353.

53. G.Q. Li, Experimental study of FRP confined concrete cylinders, Eng Struct 28(7) (2006) 1001-1008.

54. J. Mastrapa, Effect of construction bond on confinement with fiber composites, University of Central Florida, Orlando, FL, 1997. 
55. M. Saafi, H.A. Toutanji, Z.J. Li, Behavior of concrete columns confined with fiber reinforced polymer tubes, Aci Materials Journal 96(4) (1999) 500-509.

56. M.L. Moretti, E. Arvanitopoulos, Overlap length for confinement of carbon and glass FRP-jacketed concrete columns, Compos Struct 195 (2018) 14-25.

57. M.L. Moretti, Effectiveness of different confining configurations of FRP jackets for concrete columns, Structural Engineering and Mechanics 72(2) (2019) 155-168.

58. L.P.S. Kollár, George S. , Mechanics of Composite Structures, Cambridge University Press2003.

59. E.B. Richart, A.; Brown, R.L., Failure of Plain and Spirally Reinforced Concrete in Compression, Bulletin 190; University of Illinois, Engineering Experimental Station, Champaign, IL, USA, 1929.

60. J.B. Mander, M.J.N. Priestley, R. Park, Theoretical Stress-Strain Model for Confined Concrete, J Struct Eng-Asce 114(8) (1988) 1804-1826.

61. EU, Eurocode 2: Design of concrete structures, EN 1992-1-1:2004, European Union, 2004.

62. R. Benzaid, H. Mesbah, N.E. Chikh, FRP-confined Concrete Cylinders: Axial Compression Experiments and Strength Model, Journal of Reinforced Plastics and Composites 29(16) (2010) 24692488 .
63. B. Csuka, L.P. Kollar, FRP-confined circular concrete columns subjected to concentric loading, Journal of Reinforced Plastics and Composites 29(23) (2010) 3504-3520.

64. T. Ozbakkaloglu, J.C. Lim, Axial compressive behavior of FRPconfined concrete: Experimental test database and a new designoriented model, Compos Part B-Eng 55 (2013) 607-634.

65. Z.C. Girgin, Modified Johnston Failure Criterion from Rock Mechanics to Predict the Ultimate Strength of Fiber Reinforced Polymer (FRP) Confined Columns, Polymers-Basel 6(1) (2014) 5975.

66. I.W. Johnston, Comparison of two strength crieria for intact rock, ASCE Journal of Geotechnical Engineering 111 (1985) 1449-1454.

67. C.A. Coulomb, Essai sur une application des regles de maximis et minimis quelques problemes de statique, relatits a l'architecture, Paris, 1776.

68. O. Mohr, Welche Umstände bedingen die Elastizitätsgrenze und den Bruch eines Materials?, Zeitschrift des Vereines deutscher Ingenieure 44(45) (1900) 1524-1530.

69. D.G. Altman, Practical statistics for medical research, Chapman and Hall., London, 1991.

70. L.I.-K. Lin, A concordance correlation coefficient to evaluate reproducibility, Biometrics 45(255-268) (1989).

71. R.M.P. Büttner, A critical discussion of intraclass correlation coefficients, Statistics in Medicine 13(23-24) (1997) 2465-2476. 